\title{
Visuomotor Cerebellum in Human and Nonhuman Primates
}

\author{
Jan Voogd • Caroline K. L. Schraa-Tam • \\ Jos N. van der Geest • Chris I. De Zeeuw
}

Published online: 31 August 2010

(C) The Author(s) 2010. This article is published with open access at Springerlink.com

\begin{abstract}
In this paper, we will review the anatomical components of the visuomotor cerebellum in human and, where possible, in non-human primates and discuss their function in relation to those of extracerebellar visuomotor regions with which they are connected. The floccular lobe, the dorsal paraflocculus, the oculomotor vermis, the uvulanodulus, and the ansiform lobule are more or less independent components of the visuomotor cerebellum that are involved in different corticocerebellar and/or brain stem olivocerebellar loops. The floccular lobe and the oculomotor vermis share different mossy fiber inputs from the brain stem; the dorsal paraflocculus and the ansiform lobule receive corticopontine mossy fibers from postrolandic visual areas and the frontal eye fields, respectively. Of the visuomotor functions of the cerebellum, the vestibulo-ocular reflex is controlled by the floccular lobe; saccadic eye movements are controlled by the oculomotor vermis and ansiform lobule, while control of smooth pursuit involves all these cerebellar visuomotor regions. Functional imaging studies in humans further emphasize cerebellar involvement in visual reflexive eye movements and are discussed.
\end{abstract}

Keywords Flocculus · Uvula/Nodulus · Oculomotor vermis $\cdot$ Eyemovements $\cdot$ fMRI

J. Voogd $(\varangle) \cdot$ J. N. van der Geest $\cdot$ C. I. De Zeeuw

Department of Neuroscience, Erasmus MC,

Rotterdam, the Netherlands

e-mail: janvoogd@bart.nl

C. K. L. Schraa-Tam

Institute for Sales and Account Management, Erasmus University,

Rotterdam, the Netherlands

C. I. De Zeeuw

Netherlands Institute for Neuroscience,

Royal Dutch Academy of Arts and Sciences,

Amsterdam, the Netherlands

\section{Introduction}

In this paper, we will review the anatomical components of the visuomotor cerebellum in human and non-human primates and discuss their function in relation to those of extracerebellar visuomotor regions with which they are connected. Visuomotor functions of the cerebellum include control of the vestibulo-ocular and optokinetic reflexive eye movements (VOR and OKR), saccades, and smooth pursuit (SP). The cerebellar lobules with oculomotor functions that have been found in experimental anatomical and physiological studies in monkeys include the "oculomotor vermis" (lobules VI and VII), the adjacent Crus I and Crus II of the ansiform lobule, the hemisphere of the simplex lobule (HVI), the dorsal paraflocculus, the ventral paraflocculus and flocculus (together known as "floccular lobe" or "floccular complex"), and the uvula and nodulus (Fig. 1). Regions of the cerebellar nuclei with oculomotor functions are the caudal dentate nucleus, lateral posterior interposed nucleus, and caudal pole of the fastigial nucleus. While many of the cerebellar cortical structures involved in eye movement control in monkeys can be confirmed in humans with the use of modern functional imaging, those in the cerebellar nuclei in most cases still await verification at a detailed level. The homology and corresponding nomenclature of the visuomotor lobules in the human and non-human primate cerebellum are illustrated in Fig. 1.

\section{Topography of the Floccular Lobe and the Paraflocculus}

In the monkey cerebellum, the paraflocculus and flocculus are the caudal segments of the folial chain of the hemisphere that are involved in controlling the VOR and OKR. The paraflocculus forms a laterally directed loop. Its 


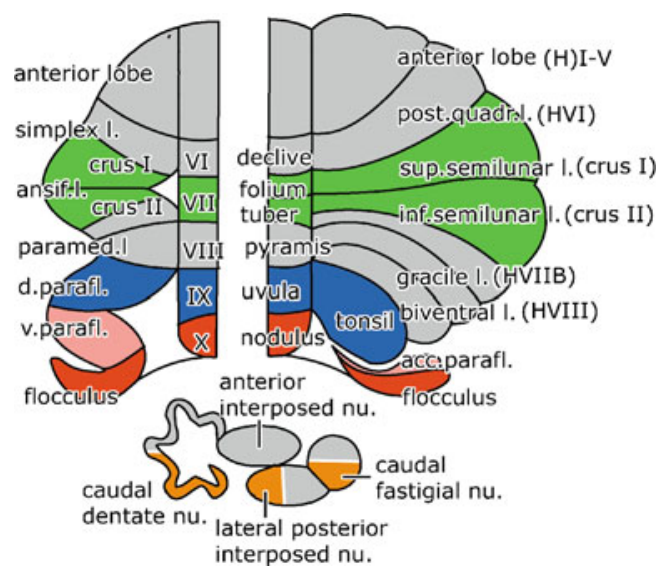

Fig. 1 Diagram of the comparative anatomical (left panel) and the classical nomenclature (right panel) of the cerebellum, illustrated in flattened maps of the cerebellar cortex of the monkey (left) and the human cerebellum (right). For the human cerebellum, we will use a modified Schmahmann nomenclature [180], using Larsell's roman numbers for the lobules of the vermis, the same numbers with the prefix $\mathrm{H}$ for the lobules of the hemisphere, Crus I and II for the superior and inferior semilunar lobules (HVIIA), retaining the classical names for the tonsil and the flocculus. Homologous lobules in monkey and human, involved in oculomotor control are indicated in the same colors. Subdivisions of the cerebellar nuclei involved in oculomotor functions are shown in orange. Abbreviations: $d$ dorsal, $l$ lobule, $n u$ nucleus, $v$ ventral

distal part is known as the lobulus petrosus because it lies embedded in a fossa of the petrosal bone. The cortices of the petrosal lobule and ventral paraflocculus are connected by a narrow cortical bridge, which forms their main functional border (Fig. 2a). In the dorsal paraflocculus and the petrosal lobule, the cortex is formed by three Purkinje cell zones $\left(D_{1}, D_{2}\right.$, and $\left.C_{2}\right)$, which are characterized by their projection to a particular cerebellar nucleus and by their input from the climbing afferents that are derived from a specific subdivision of the inferior olive (Fig. 2b). $\mathrm{D}_{1}$ and $\mathrm{D}_{2}$ project to the caudal and rostral parts of the dentate nucleus, respectively; $\mathrm{C}_{2}$ projects to the posterior interposed nucleus. The $\mathrm{C}_{2}$ zone is present in the entire cerebellum and continues from the distal part of the petrosal lobule via the ventral paraflocculus into the flocculus. In the floccular lobe, the two D zones are replaced by three [1], in lower mammals four [2], floccular zones with projections to the vestibular nuclei and a small ventral part of the dentate nucleus. The zonal arrangement of the corresponding lobules of the human cerebellum has not been studied. The homologies of the human tonsil with the monkey dorsal paraflocculus and of the human accessory paraflocculus with the monkey ventral paraflocculus are supported by comparative anatomical studies in the great apes (Voogd, unpublished observations). The human tonsil differs mainly from the monkey dorsal paraflocculus in that the width of its folia is enlarged and that its loop is directed medially (Fig. 2c).
Fig. 2 Diagrams of the ventral surface of the macaque (a) and the caudal aspect of the human cerebellum (c) showing the direction of the folial chain of the paraflocculus and the flocculus and their human homologs as a red line. The zonal composition of these lobules in the monkey cerebellum is shown in $\mathbf{b}$. Abbreviations: $A N T$ anterior lobe, $V P F L$ ventral paraflocculus, FLOC flocculus, PETR petrosal lobule, $D P F L$ dorsal paraflocculus, $P M D$ paramedian lobule, $1-3$ floccular zones F1-F3

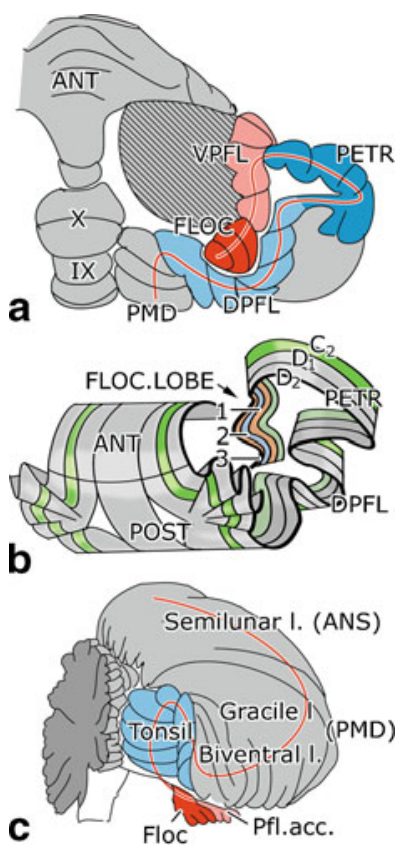

\section{Pathways Underlying VOR and OKR: Connections with the Floccular Lobe}

The floccular lobe is part of a loop that is superimposed on the basic pathways mediating the VOR and probably also the OKR, and in addition, it probably also serves as an output control system for SP. The three-neuron reflex path of the VOR consists of the ganglion cells of the vestibular ganglion, the inhibitory and excitatory oculomotor relay cells in the medial and superior vestibular nucleus and group $\mathrm{Y}$, and the motor neurons of the oculomotor nuclei (Fig. 3). The three pairs of external eye muscles rotate the eyeball in three perpendicular planes that are approximately parallel to the planes of the three semicircular canals [3]. The pathway for the OKR includes the nucleus of the optic tract (NOT), which receives a retinal input from the contralateral eye. Interestingly, the NOT in primates is also innervated by afferents from striate and extrastriate cortical areas such as the middle temporal (MT) and the middle superior temporal (MST) motion-sensitive areas [4]. A projection of the NOT to the vestibular nuclei has been substantiated in monkeys [5, 6], but not in the rabbit [7], The nucleus prepositus hypoglossi, which receives afferents from the NOT, is a link in an alternative NOT vestibular pathway.

The floccular lobe receives mossy fibers mainly from sources carrying vestibular, visual, and eye movement information. The flocculus projects to the oculomotor relay cells of the vestibular nuclei $[8,9]$. The projections of the individual floccular zones have been established in rabbits [10]. These projections, presumably, are very similar in monkeys, but for the absence of the F4 zone. Purkinje cells of the floccular zones F1 and F3 project to the oculomotor relay cells in the superior vestibular nucleus and group $\mathrm{Y}$ 


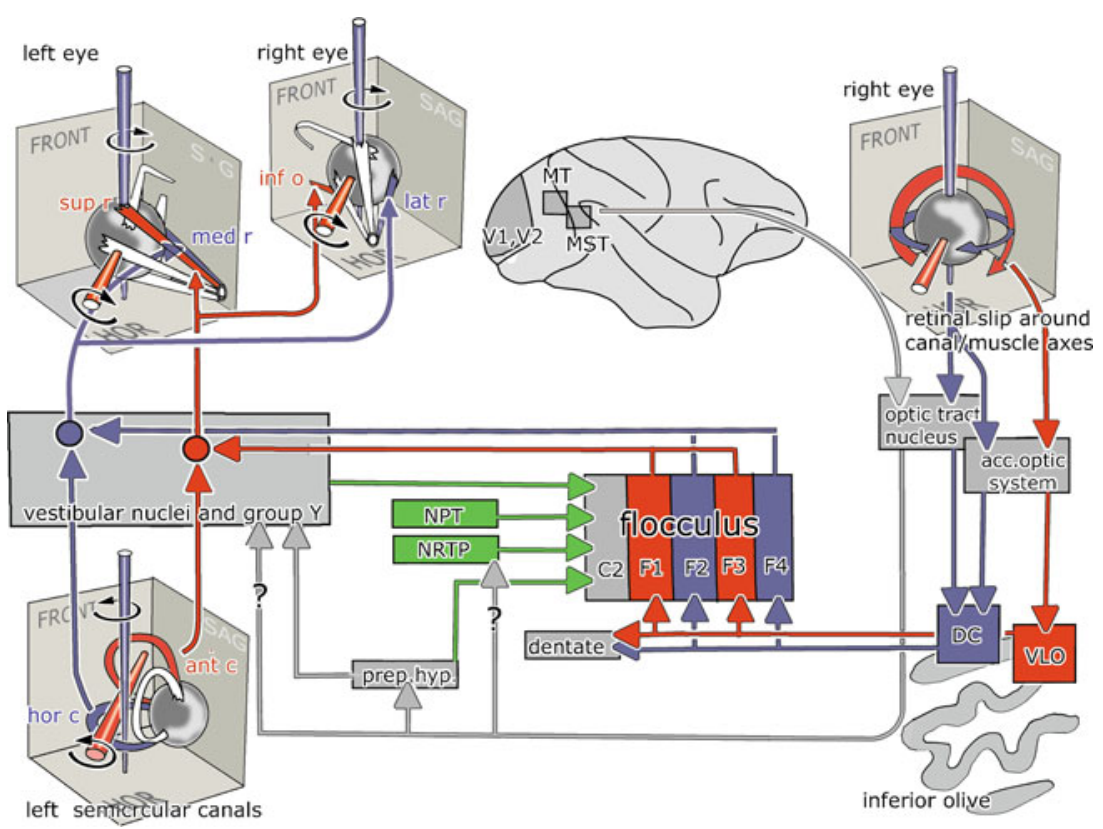

Fig. 3 The reflex pathway of the VOR and the OKR and their connections with the floccular lobe. Pathways for eye movements around a vertical axis are indicated in blue, for movements around an oblique horizontal axis at $45^{\circ}$ azimuth in red. Mossy fiber pathways are shown in green. Question marks indicate disputed projection of the nucleus of the optic tract to the vestibular nuclei and the nucleus reticularis tegmenti pontis. Abbreviations: ant/hor $c$ anterior/horizon-

that move the eyes about an oblique horizontal axis that is colinear with the axis of the ipsilateral anterior semicircular canal $[11,12]$, while those in floccular zones F2 and F4 (in monkeys, F2 only) project to oculomotor relay cells in the medial vestibular nucleus that moves the eyes about a vertical axis. The Purkinje cells in the floccular $\mathrm{C}_{2}$ zone project to the posterior interposed nucleus and presumably control head movements [13]. In the rabbit flocculus, one can also identify Purkinje cells in the F1 zone that project to a small part of the ventral dentate [10]. Although not illustrated in Fig. 3, these floccular zones also project to inhibitory oculomotor relay cells that connect with the antagonistic muscles [8].

\section{Climbing Fiber Projections to the Floccular Lobe}

Each of the floccular zones receives climbing fibers from a particular subdivision of the contralateral inferior olive (Fig. 3). Neurons of the nuclei of the accessory optic system and the NOT in the mesencephalon receive information on global movements of the visual surround from large-field ganglion cells in the contralateral retina via the optic tract. These movements generate retinal slip signals, which can serve as an error signal in long-term adaptation of the VOR and OKR. The 3-D organization of the climbing fiber input to the flocculus has been mainly studied in rabbits [14]. The tal canal, DC dorsal cap, FRONT frontal plane, HOR horizontal plane, inf/sup o inferior/superior oblique muscle, med/lat/sup/inf $r$ medial/ lateral/superior/inferior rectus muscle, MST medial superior temporal area, $M T$ middle temporal area, $N P T$ nuclei of the paramedian tracts, NRTP nucleus reticularis tegmenti pontis, Prep hyp nucleus prepositus hypoglossi, VLO ventrolateral outgrowth

retinal ganglion cells that signal slip about the vertical axis excite neurons of the NOT and the dorsal nucleus of the accessory system. These nuclei project to the caudal dorsal cap (DC) of the ipsilateral inferior olive, which in turn provides the climbing fibers to floccular zones F2 and F4 on the contralateral side $[15,16]$. In contrast, the climbing fiber signals in the flocculus that modulate optimally about a horizontal axis that is close to perpendicular to the ipsilateral anterior semicircular canal are transmitted bilaterally by the medial and lateral nuclei of the accessory optic system and contralaterally by the visual tegmental relay zone. These nuclei project to the rostral dorsal cap and ventrolateral outgrowth (VLO) of the inferior olive, which in turn provide climbing fibers to the contralateral floccular zones F1 and F3 (Fig. 3). While the organization of the accessory optic system and the projections of its subnuclei to the inferior olive in primates has been found to be very similar to those in lower mammals [17], only the projection of the caudal dorsal cap to the $\mathrm{F} 2$ zone has been substantiated in monkeys $[1,18]$.

\section{Mossy Fiber Input to the Floccular Lobe}

Apart from its vestibular mossy fiber afferents that are mainly derived from the medial and superior vestibular nuclei [18], the floccular lobe receives various mossy fiber 
inputs that carry visual or eye movement signals (Figs. 3 and 8). These signals are mediated via the nucleus prepositus hypoglossi [19], the nuclei of the paramedian tract [20], and the nucleus reticularis tegmentis pontis (NRTP) [18], which forms a relay in crossed tectocerebellar and corticocerebellar pathways involving the frontal eye fields (Figs. 5 and 7). A projection from the NOT to the NRTP is still controversial. It was documented in monkeys with the use of anterograde tracing $[5,6]$, but not confirmed with the use of retrograde tracing $[5,6,21]$. Moreover, this projection has not been found in rabbits or rats, neither with anterograde nor with retrograde tracing [7, 22, 23].

Contrary to what is described by Langer et al. [18], a substantial projection of the dorsolateral pontine nuclei to the floccular lobe appears to be absent. The dorsolateral pontine nuclei mainly target the dorsal paraflocculus, with weaker terminations in the ventral paraflocculus, uvula, paramedian lobule, and Crus II and a minor projection to lobule VII (Fig. 4). Moreover, retrograde labeling from the floccular lobe was limited to the NRTP $[24,25]$.

Lesions of the NRTP reduce the gain of the OKR in both rats and rabbits [26, 27], which supports the possibility that optokinetic signals are mediated by this nucleus. Yet, as indicated above, it remains to be demonstrated whether these signals originate in the NOT or not. It is possible that such signals are relayed to the cerebellum via the nucleus

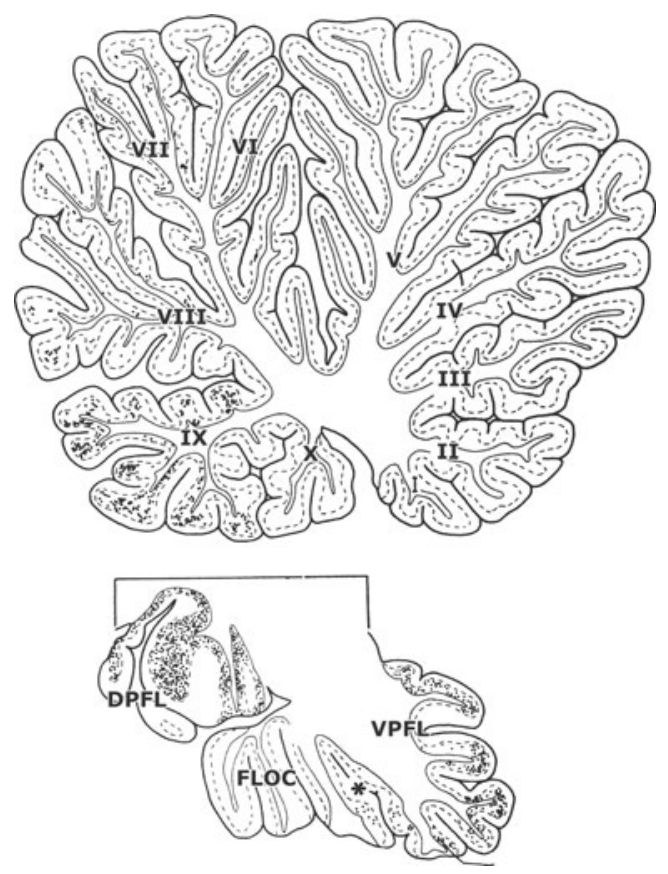

Fig. 4 Sagittal sections through the cerebellar vermis, the floccular lobe, and the dorsal paraflocculus of a macaque monkey showing the distribution of the antegrade axonal tracer WGA-HRP injected in the dorsolateral pontine nuclei [24]. Asterisk indicated position of the posterolateral fissure. Abbreviations: !- $X$ lobules $I-X$ of the vermis, $D P F L$ dorsal paraflocculus, FLOC flocculus, $V P F L$ ventral paraflocculus prepositus hypoglossi because this nucleus does receive a direct input from the nucleus of the optic tract and it projects directly to the floccular lobe.

The medial and lateral nuclei of the accessory optic system and the visual tegmental relay zone mediate retinal slip signals to the nuclei of the paramedian tract. Thus, the optokinetic signals mediated by the nucleus prepositus hypoglossi and NRTP as well as by the nucleus of the paramedian tract to the floccular complex may very well be involved in adaptation of the VOR and/or OKR [28-30]. The nucleus prepositus hypoglossi and nuclei of the paramedian tract are probably particularly involved in horizontal and vertical gaze control, respectively.

The VOR in monkeys is a highly modifiable reflex [31]. When head turns are consistently associated with image motion across the retina, the VOR undergoes changes in gain and/or phase shifts that are in the correct direction to improve the compensatory nature of the eye movements [32-34]. Electrophysiological recordings from neurons in the floccular lobe and vestibular nuclei indicate that both regions are highly plastic and have multiple potential mechanisms that may underlie adaptation of the VOR [32, 33, 35-39]. Although controversial, changes of simple spike activities of Purkinje cells in the floccular lobe during this adaptation may represent themselves as a change not only in head velocity sensitivity but also in eye velocity sensitivity [40, 41].

\section{Pathways Underlying Saccadic Eye Movements}

The oculomotor vermis (lobule VII and adjacent lobule VI) are concerned with the control and adaptation of saccades and SP [42]. They project to the brain stem saccadegenerating system through the caudal pole of the fastigial nucleus (Fig. 5). Efferent fibers of the caudal fastigial nucleus cross within the cerebellar commissure and terminate in the vestibular nuclei and in several components of the saccade-generating system such as the excitatory and inhibitory burst neurons (EBNs and IBNs) in the pontine paramedian reticular formation, the prepositus hypoglossi nucleus, the interstitial nucleus, and the rostral interstitial nucleus of the medial longitudinal fascicle [43]. In addition, the caudal pole of the fastigial nucleus projects contralaterally to the NRTP and the dorsolateral and dorsomedial pontine nuclei and bilaterally to the rostral pole of the superior colliculus. This region of the superior colliculus is involved in control of SP [44]. Thalamocortical projections of the fastigial nucleus have not been studied in monkeys.

The superior colliculus is involved in the generation of saccades and associated head movements. The primate superior colliculus is connected with the brain stem through the predorsal fascicle that decussates in the mesencephalon [45]. Its targets among the nuclei of the saccade-generating 


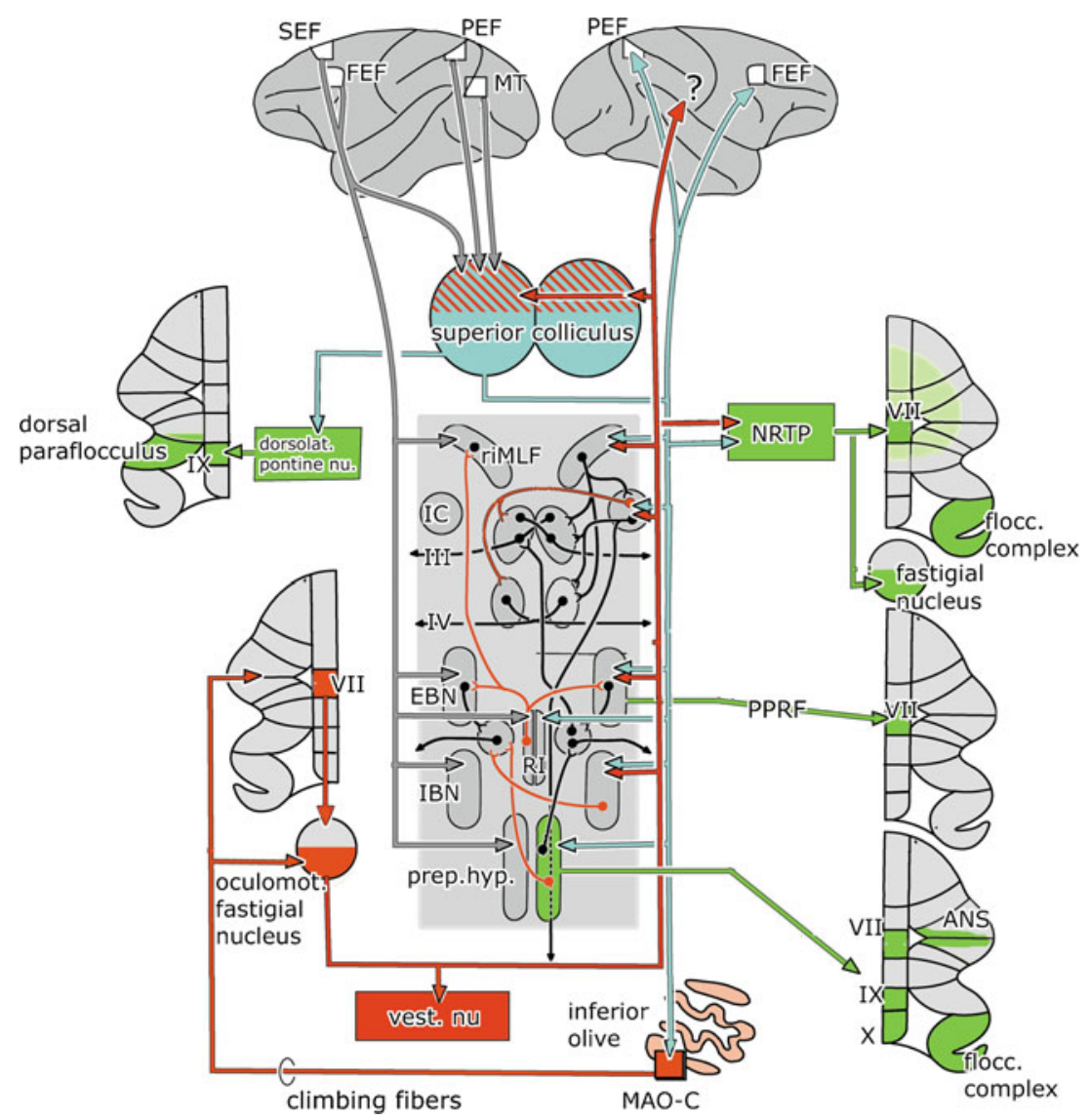

Fig. 5 The cerebellum and the brain stem saccade-generating system. The saccade-generating system is shown in the center of the figure. It is composed of EBNs and IBNs, located in the pontine paramedian reticular formation. These EBNs and IBNs project to the abducens nucleus (Fig. 4). IBNs and EBNs for vertical and rotatory nucleus eye movements are located in the rostral interstitial nucleus of the medial longitudinal fascicle (riMLF) and in Cajal's interstitial nucleus in the mesencephalon. Gaze holding is achieved by integration of the velocity signal issued by the EBNs by neurons of the prepositus hypoglossi and interstitial nucleus. Mossy fiber connections (green), cerebellar nuclear efferents and afferent climbing fiber connections

system are very similar to those of the caudal fastigial nucleus. In addition, it provides via a contralateral collateral system the predorsal fascicle an input to the thalamus and from there to the frontal eye field (FEF). The FEF and supplementary eye fields (SEF) in the frontal lobe, in turn, provide a major afferent input to the saccade-generating system in the brain stem (Fig. 5). Moreover, just like the NOT, the superior colliculus also projects to the cerebellum via both the climbing and mossy fiber system.

The climbing fiber route from the superior colliculus is mediated by subnucleus B (in rodents $\mathrm{C}$ ) of the caudal medial accessory olive (Fig. 5), which directly innervates the oculomotor vermis [46] and, in nonprimates at least, the caudal pole of the fastigial nucleus [47]. In rodents, the oculomotor vermis receives an additional projection from the group beta [48]. The rodent tecto-olivocerebellar (red), projections from the superior colliculus (blue), and the visual cortical areas (gray) are shown. Abbreviations: $A N S$ ansiform lobule, $E B N$ excitatory burst neurons, $F E F$ frontal eye field, $I B N$ inhibitory burst neurons, $I C$ interstitial nucleus of Cajal, $M T$ middle temporal area, $P E F$ parietal, eye field (lateral intraparietal area LIP), $P P R F$ pontine paramedian reticular formation, $M A O-C$ subnucleus $\mathrm{C}$ of the caudal medial accessory olive, Prep.hyp. prepositus hypoglossi nucleus, $R I$ nucleus raphes interpositus, riMLF rostral interstitial nucleus of the medial longitudinal fascicle, $S E F$ supplementary eye field

climbing fiber path from subnucleus $\mathrm{C}$, in addition, includes a projection to the Al zone [49]. This zone appears to be absent in carnivores and primates. Mossy fiber projections from the superior colliculus to the oculomotor vermis are mediated by the NRTP, the dorsomedial and dorsolateral pontine nuclei, the prepontine reticular formation, and the prepositus hypoglossi nucleus [46]. The crossed projection of the superior colliculus to the NRTP terminates in its medial part, which also receives input from the caudal oculomotor region of the fastigial nucleus, the FEF, and other visuomotor afferents [21] (Figs. 5 and 7). The oculomotor vermis may share some of the projections from the FEF that are relayed through the dorsomedial pontine nuclei to the ansiform lobule. The mossy fibers of the dorsolateral pontine nuclei mainly target the dorsal paraflocculus [25]. A projection from postrolan- 
dic cortical areas to the oculomotor vermis appears unlikely. As described above, the projection of the NRTP is not only restricted to the oculomotor vermis but also includes the floccular lobe and may extend into other parts of the cerebellum [50,51]. In cats and rats, it also supplies a collateral projection to the caudal pole of the fastigial nucleus, the ventrocaudal dentate, and the lateral posterior interposed nucleus [52-54] (Fig. 7).

The mossy fiber projection from the prepositus hypoglossi is one of the few mossy fiber systems for which the distribution in primates is completely known [19]. Apart from the oculomotor vermis, it includes the ansiform lobule and the floccular lobe, as well as the uvula (IX) and nodulus (lobule X). Its distribution, therefore, covers a very large part of oculomotor cerebellum. Principal neurons of this nucleus collateralize extensively in the brain stem; small neurons project to the inferior olive and multidendritic cells to the flocculus. Yet the types of cells that give rise to other cerebellar projections remain to be determined [19, 55-57].

Just like compensatory eye movements, saccades form an excellent behavior tot test cerebellar motor learning because one can gradually modify the amplitude of a saccade if the target moves consistently while a saccade is being made $[58,59]$. The cerebellum presumably exerts its main control on saccadic adaptation via the Purkinje cells in the oculomotor vermis that project to the caudal fastigial nucleus. As explained above, the neurons in this part of the fastigial nucleus innervate the EBNs and IBNs in the contralateral brain stem, which in turn drive abducens motoneurons to produce saccades [60]. Interestingly, changes in simple spike activities of many, but not all, Purkinje cells in the oculomotor vermis can be correlated to the level of adaptation of the saccadic eye movements in primates $[59,61]$. These data are compatible with physiological studies in monkeys, which showed that when the saccadic control areas, lobules VI and VII, are lesioned [62-64] or microstimulated during saccadic displacement [65] they consistently make dysmetric saccades

When the caudal fastigial nucleus is disabled, saccade gains are more variable, contraversive saccades are too small and ipsiversive saccades too large. This suggests that each saccade is missing a contraversive component, driving the eyes to the contraversive site. Caudal fastigial neutrons discharge a burst of action potentials for every saccade, whatever its direction or size. The pattern of burst timing suggests that bursts, associated with the beginning of contraversive saccades, help to accelerate them whereas bursts at the end of ipsiversive saccades decelerate them, preventing overshooting [42]. Lesions of the oculomotor vermis abolish the ability to adapt saccades [66]. Caudal fastigial neurons have been shown to increase their bursts and/or to exhibit them earlier during adaptative reduction in size of ipsiversive saccades or adaptive increase of contraversive saccades [67]. Adaptation is presumably mainly effected by appropriate changes in the firing of the contralateral IBNs that project to the oculomotor nuclei [68].

Apart from the oculomotor vermis and the caudal fastigial nucleus, saccade-related neurons are present in the ventrolateral posterior interposed nucleus and the ventrocaudal dentate, nuclei which are the target nuclei of the dorsal paraflocculus and the ansiform lobule. Bilateral inactivation of the posterior interposed nucleus deprives all saccades of a downward component and reduces upward acceleration and downward deceleration [69]. The responsible pathway for these effects, probably, is the projection of the posterior interposed nucleus to the superior colliculus. Thus, the nervous system probably modulates the amplitude of the ocular saccade by tuning the inhibitory action exerted by the vermal Purkinje cells on the fastigial nuclei and possibly also by extravermal Purkinje cells, which target other cerebellar nuclei.

\section{Pathways Underlying Smooth Pursuit Eye Movements}

As indicated above, SP control systems partly share those for compensatory eye movements and saccadic eye movements. However, in all cases, they critically depend on a neocortical network, with the MT, the MST, and the FEF as its main hubs (Figs. 6 and 7). Included in this network are the SEF and the parietal eye field (PEF), also known as the lateral intraparietal (LIP) area. Visual signals flow from the primary visual cortex to MT, where the firing of neurons encodes image motion in a retinal coordinate system. MST neurons encode both retinal and extraretinal events and convert the signals into a spatial coordinate system. Gain control of SP takes place in a separate subdivision of the FEF, the frontal pursuit area. It should be noted that the same neocortical network is also involved in the generation and control of saccades and that a corresponding frontal saccade area is present in the FEF [70]. The final paths for SP presumably pass through the cerebellum as ablation of the cerebellum seriously impairs SP [42]. Regions involved

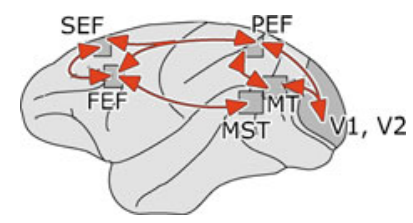

Fig. 6 Diagram of the cortical network involved in smooth pursuit. Abbreviations: $F E F$ frontal eye field, $M S T$ medial superior temporal area, $M T$ middle temporal area, $P E F$ parietal eye field (lateral intraparietal area), $S E F$ supplementary eye field, $V 1, V 2$ primary and secondary visual areas 
Fig. 7 Cerebellar connections involved in smooth pursuit. Mossy fiber projections from the frontal eye fields are shown in red and from the postrolandic visual areas in green. Cerebellocortical-olivary climbing fiber loops of the $\mathrm{C}_{2}$ zone and the posterior interposed nucleus are shown in blue, the $\mathrm{D}_{1}$ zone and the caudal dentate nucleus loop in orange; its hatched segments have not yet been verified in primates. Abbreviations: $A i$ anterior interposed nucleus, $C_{2}, C_{2}$ Purkinje cell zone, $D_{l}, D_{l}$ Purkinje cell zone, $F$ fastigial nucleus, $F E F$ frontal eye field, MST medial superior temporal area, $M T$ middle temporal area, $N R T P$ nucleus reticularis tegmenti pontis, $P E F$ parietal eye field (lateral intraparietal area), $P I$ posterior interposed nucleus, $S E F$ supplementary eye field, $V 1, V 2$ visual areas 1 and 2

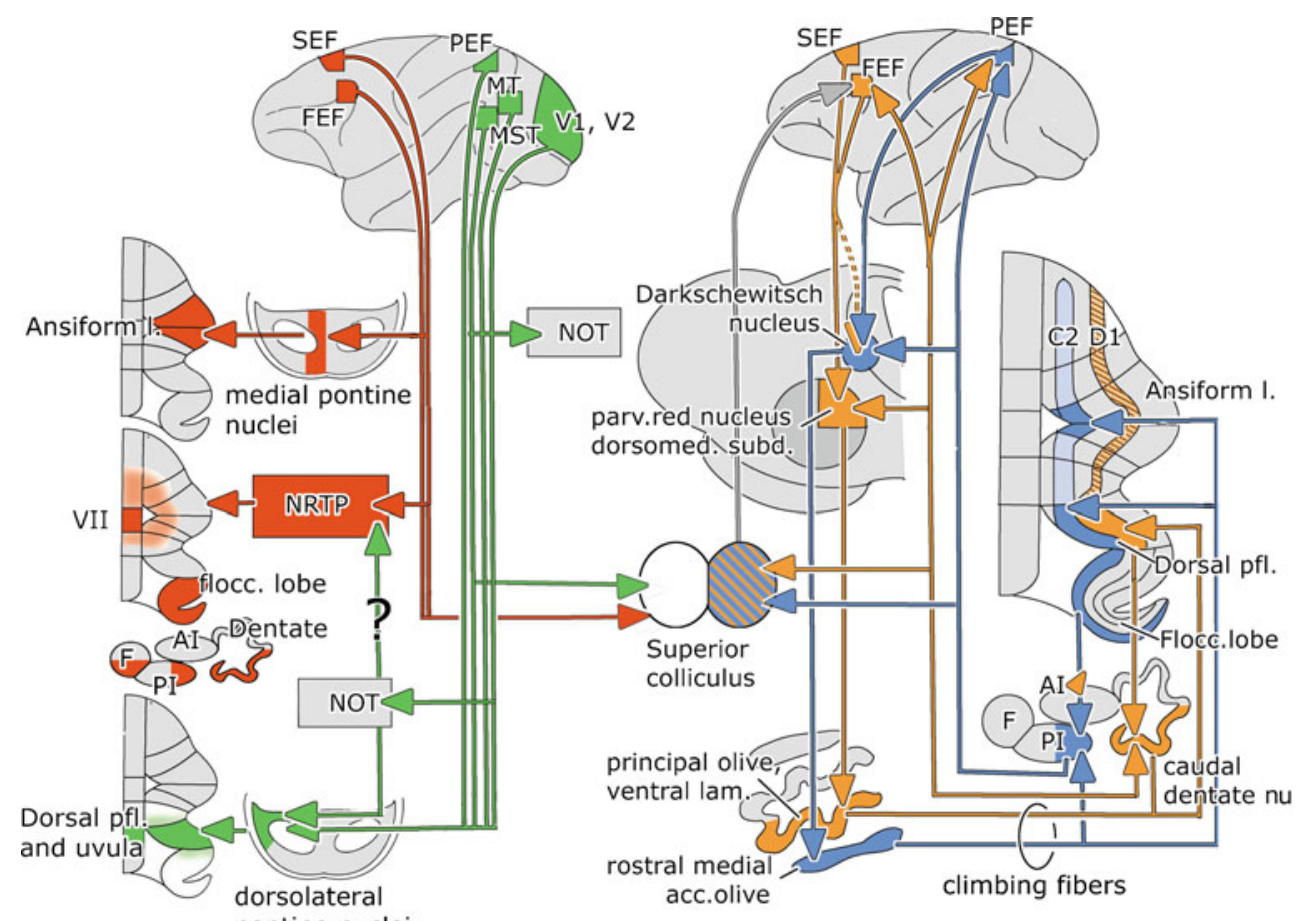

nuclear efferents and climbing fiber afferents are the floccular lobe, the oculomotor vermis and the adjacent ansiform lobule, the dorsal paraflocculus, and the uvula.

Inputs from postrolandic visual areas (PEF, MT, MST, $\mathrm{V} 1$, and V2) descend in the cerebral peduncle and project to the dorsolateral pontine nuclei $[24,25,71-76]$. In addition, the dorsolateral pontine nuclei receive afferents from the ipsilateral superior colliculus [77] and the NOT [5-7, 23]. The dorsolateral pontine nuclei give rise to a mossy fiber projection that terminates, mainly contralaterally, in the dorsal paraflocculus and uvula [24, 25] (Fig. 7).

The SEF projects exclusively to the medial pontine nuclei, while the FEF provides an additional projection to the dorsal and dorsolateral pontine nuclei [78-82]. The FEF-receiving pontine nuclei project to the ansiform lobule, a connection that has been verified with combined retrograde and antegrade axonal transport [83]. The pontine projections of the FEF and the postrolandic visual areas do not overlap. Access of the FEF and SEF to the floccular lobe and the oculomotor vermis is provided by their bilateral projections to the NRTP. The mossy fiber connections of this nucleus to the ansiform lobule, which are rather extensive in cat [51], are scarce in monkeys [50]. With respect to the projections of the frontal SP and saccade areas, there are no obvious differences in their pontine and reticular tegmental mossy fiber projections. A relatively direct access to the floccular lobe, oculomotor vermis, and ansiform lobule is therefore limited to the FEF and SEF. A more indirect route from the cerebral cortex to the cerebellum may be available from the postrolandic visual areas through their pathway to the NRTP or the nucleus prepositus hypoglossi via the NOT. However, the pathway from the NOT through the NRTP is still controversial (Fig. 6).

SP eye-movement-related activity can be recorded from the rostral NRTP [84]. Saccades appear to be controlled by its caudal portion [85]. Chemical lesions of the NRTP cause deficits both in the initiation and maintenance of SP. These deficits recover within a couple of days [86]. Neurons in the dorsolateral pontine nuclei are responsive to both discrete and large-field visual motion. Their properties are very similar to the neurons in MT and MST, areas that provide the input to the dorsolateral pons. Bilateral focal lesions of the dorsolateral pontine nuclei cause short-lasting deficits in the initiation of SP and in steady-state tracking [8789]. The visuomotor properties of the NRTP and the dorsolateral pons differ because the former contributes both to the initiation and maintenance of SP, whereas the latter plays a larger role in maintaining steady-state SP eye velocity. Moreover, gaze velocity neurons in the NRTP were modulated during head movement [90, 91]. In accordance with these observations, lesions of the petrosal lobule of the dorsal paraflocculus, the main target of the dorsolateral pons, caused long-lasting decrease of postsaccadic SP [92]. No data are available on the properties of the dorsomedial pontine neurons that receive input from the FEF. Lesions of their target, the ansiform lobule, cause a delay in the onset of SP movements and a decrease in postsaccadic SP pursuit velocity. Similar tendencies have 
been observed in the onsets and amplitudes of saccades [93]. Visuomotor activity of Purkinje cells has been reported in the dorsal paraflocculus [94] and the ansiform lobule [95]. Neurons of the lateral pole of the posterior interposed nucleus and the ventral dentate, target nuclei of both of these lobules, discharge during saccades. For the posterior interposed nucleus, these bursts occur during upward or downward saccades. Bilateral inactivation of this nucleus deprives all saccades from a downward component [42].

As indicated in the above primates, the NOT is not only innervated by the retinal direction-sensitive ganglion cells [96] that are required for generation of the optokinetic signals but also by afferents from postrolandic visual areas such as the medial superior temporal cortex, which probably contribute to motion perception and SP [4, 97] (Fig. 3). Therefore, it is parsimonious to expect that the mossy fiber inputs of these latter visual and eye movement sources somehow also interact downstream with the climbing fiber activity in the cerebellum during SP learning. Medina and Lisberger [98] indeed recently showed in the floccular lobe of monkeys that the presence of climbing fiber activities on single learning trials can be linked to a depression of simple spike responses in the same Purkinje cells on the subsequent trial, at a time when SP learning is expressed. Thus, since the simple spike responses of Purkinje cells are to a large extent determined by their input from the mossy fiber-parallel fiber pathway, while their climbing fiber activities are determined by activities in the inferior olive, we can conclude that activities of the visual mossy fiber inputs to the primate floccular lobe ultimately integrate with those of its visual climbing fiber inputs during SP learning.

\section{Cerebro-cerebellar Climbing Fiber Loops Putatively Involved in Eye Movements}

Climbing fiber paths from cerebral cortical areas to the cerebellum that may be involved in eye movement coordination have only been considered relatively infrequently. They are part of two parallel recurrent loops (Fig. 7). One of these loops contains the lateral visual portion of the posterior interposed cerebellar nucleus [99], the target nucleus of the $\mathrm{C}_{2}$ Purkinje cell zone. This zone extends over the entire cerebellum, from the anterior lobe into the flocculus. Its segments located in the ansiform lobule, the dorsal paraflocculus, and the floccular lobe project to the lateral portion of the posterior interposed nucleus. This region of the nucleus is connected at the mesencephalo-diencephalic border with the contralateral Darkschewitsch nucleus [100, 101], with the near-response region located dorsal to the oculomotor nuclei, which is required for vergence eye movements [102], and via the thalamus with the PEF [103] (ventral area LIP), which is located in the inferior bank of the intraparietal sulcus. Inferior parietal area 7, presumably including PEF cells, projects to Darkschewitsch nucleus [104]. This nucleus innervates the rostral medial accessory olive through the medial tegmental tract [105]. The rostral pole of this nucleus provides the ansiform, dorsal parafloccular, and floccular segments of the $\mathrm{C}_{2}$ zone with their climbing fibers and the interposed cerebellar nucleus with a collateral innervation. Interestingly, electrical stimulation of the $\mathrm{C}_{2}$ zone in the flocculus elicits short-latency head movements [13], which suggests that control of compensatory eye and head movements can in principle be integrated in the floccular lobe.

The caudal dentate, which forms the core element of the other recurrent loop, is the target nucleus of the $\mathrm{D}_{1}$ zone of the dorsal paraflocculus [25]. The presence of this zone in more rostral lobules of the monkey cerebellum appears likely [106-108]. The caudal dentate projects to the dorsomedial subnucleus of the parvocellular red nucleus and as a thalamocortical pathway to the FEF and PEF [70, 85, 103]. The FEF and SEF in turn project to the dorsomedial parvocellular red nucleus [78-81, 109, 110]. A projection from $\mathrm{PEF}$ in the inferior bank of the intraparietal sulcus to the red nucleus appears to be absent [111], while a FEF projection to Darkschewitsch nucleus is still disputed (Fig. 7). The dorsomedial subnucleus of the parvocellular red nucleus innervates the ventral lamina of the principal olive [112]. This subnucleus projects to the $D_{1}$ zone and the caudal dentate nucleus $[48,113]$. In the dorsal paraflocculus, therefore, mossy-parallel fiber systems from postrolandic areas may interact with $\mathrm{D}_{1}$ climbing fibers from the frontal visual areas and $\mathrm{C}_{2}$ climbing fibers from the PEF. In the ansiform lobule, the floccular lobe and the oculomotor vermis climbing fibers may interact with mossy-parallel fiber systems from the FEF. In the ansiform lobule, these interactions concern climbing fibers from the $\mathrm{C}_{2}$ and $\mathrm{D}_{1}$ zones; in the floccular lobe, they concern climbing fibers from the $\mathrm{C}_{2}$ zone derived from the rostral medial accessory olive, and in the oculomotor vermis, the tecto-olivary climbing fibers are derived from the caudal medial accessory olive.

\section{Nodulus and Uvula}

The anatomy and oculomotor physiology of the nodulus and the uvula have recently been reviewed in detail by Barmack [114, 115]. The nodulus and the uvula are separated by the posterolateral fissure. The main functional border, however, is located between dorsal and ventral parts of the uvula. Whereas the main input to the dorsal uvula stems from the pontine nuclei, the nodulus and the ventral 
uvula are dominated by inputs from the vestibulocerebellar mossy fiber afferents. In rabbits, primary vestibulocerebellar mossy fibers from the vestibular nerve terminate ipsilaterally in the nodulus and ventral uvula and more sparsely in the bottom of the large fissures. They are absent in the flocculus [116]. Semicircular canal input prefers the nodulus; afferents from the sacculus preferentially terminate in the ventral uvula; a preference of utricular afferents has been reported for either of the two lobules [117-121].

Secondary vestibulocerebellar mossy fibers, which also innervate the flocculus, terminate bilaterally in the same parts of the nodulus and uvula (Fig. 8 [122]). They take their origin from the caudal medial vestibular nucleus and the periphery of the superior vestibular nucleus. The former projection is mostly cholinergic [123]. A partial reciprocity has been found for the connections between the vestibular nuclei and the cerebellum.

The mossy fiber-parallel fiber pathway is responsible for the simple spike modulation of Purkinje cells. In the uvulanodulus of the mouse, parallel fiber length approximates the total width of these lobules $(2.7-2.9 \mathrm{~mm})$. Topographic specificity of preferred simple spike modulation can therefore probably not be directly attributed to the parallel

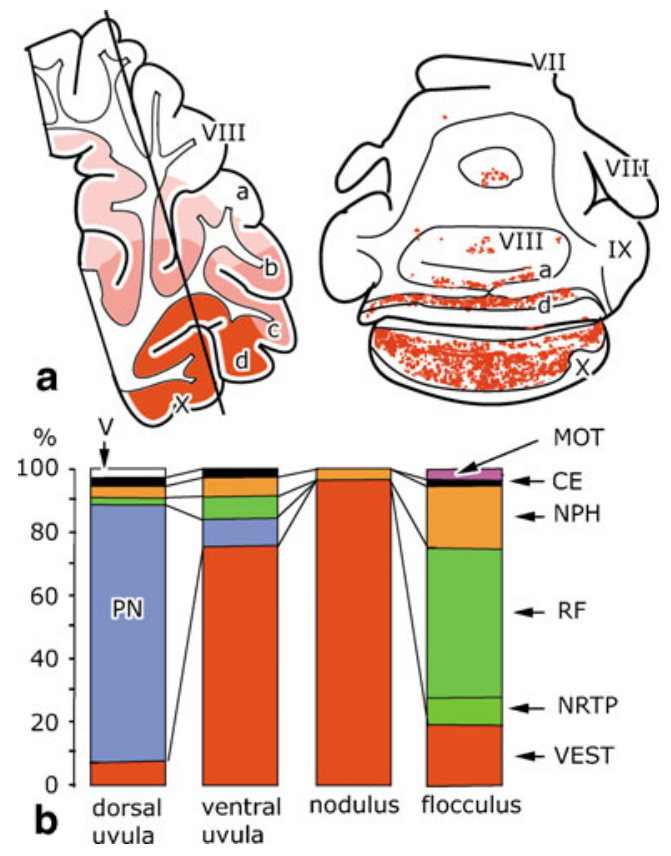

Fig. 8 Mossy fiber projections to the nodulus-uvula and the flocculus. a Distribution of secondary vestibulocerebellar mossy fibers in the rabbit. The line in the sagittal section indicates the level of the transverse section. Redrawn from Thunissen et al. [122]. b Percentages of mossy fiber terminals from different sources in the uvulanodulus and the flocculus of the cat. Redrawn from Sato et al. [181] and Akoagi et al. [182]. Abbreviations: VII-X lobules VII-X of Larsell, $P N$ pontine nuclei, $M O T$ motor nuclei, $C E$ external cuneate nucleus, $N P H$ nucleus prepositus hypoglossi, $R F$ reticular formation, NRTP nucleus reticularis tegmenti pontis, VEST vestibular nuclei, $V$ sensory trigeminal nuclei fiber input [124], but in principle, it might result from a dominant impact of the ascending granule cell axons and/or from heterosynaptic effects of the climbing fiber inputs. According to Yakusheva and Angelaki [125-127], simple spike responses of Purkinje cells in the uvula and nodulus of the monkey constitute a homogeneous population that encodes inertial motion. Purkinje cells derive an estimate of head attitude by encoding the temporally integrated earth horizontal rotational component of the angular velocity signal of the semicircular canals. This value could then be subtracted from linear acceleration provided by the otoliths and used to estimate inertial motion during navigation. The preferred directions for both otolith-driven and canal-driven components of the simple spike response are precisely matched for each Purkinje cell and are clustered close to the axes of the anterior and posterior semicircular canals

The main mossy fiber projection to the dorsal uvula takes its origin from the pontine nuclei, in primates from its dorsolateral subdivision (Fig. 4). Nodulus and uvula receive minor projections from other sources such as the nucleus prepositus hypoglossi (Fig. 8).

Climbing fibers terminate in a complicated array of longitudinal zones in the nodulus and the uvula. In rats, their projections were established with antegrade labeling from small injections into the subnuclei of the inferior olive, using the banding pattern of zebrin-positive and zebrin-negative Purkinje cells as a template [128] (Fig. 9a). In the nodulus, climbing fibers relaying optokinetic information are arranged in three zones. Climbing fibers innervated by the DC are located in medial and the lateral zones and those from the VLO occupy an intermediate position. These zones extend for some distance on the ventral surface of the uvula. The DC-innervated zones are separated from the VLO-innervated zone by projections from the rostral group beta. The group beta and the dorsomedial cell column (DMCC) relay input from the labyrinth. The borders of these zones are not visible in the zebrin pattern because all Purkinje cells in the nodule are zebrin positive. In the uvula, three narrow bands of zebrin-negative Purkinje cells separate the wider zebrin-positive bands 1-4. Purkinje cells of zebrinpositive band 1 and the medial half of band 2 are innervated by climbing fibers of the caudal group beta; the rostral beta supplies climbing fibers to lateral band 2 and medial band 3, the DMCC innervates lateral band 3 and band 4 . The narrow, zebrin-negative strips in the uvula receive climbing fibers from the dorsomedial group and the caudal medial accessory olive. These nuclei transmit somatosensory information from the trigeminal nuclei. For the DC- and VLO-innervated zones, this pattern was confirmed in a study showing collateralization of climbing fibers between these zones and similar zones in the flocculus [129] (Fig. 3). Climbing fiber projections of the group beta and the dorsomedial cell column and the innervations of the 

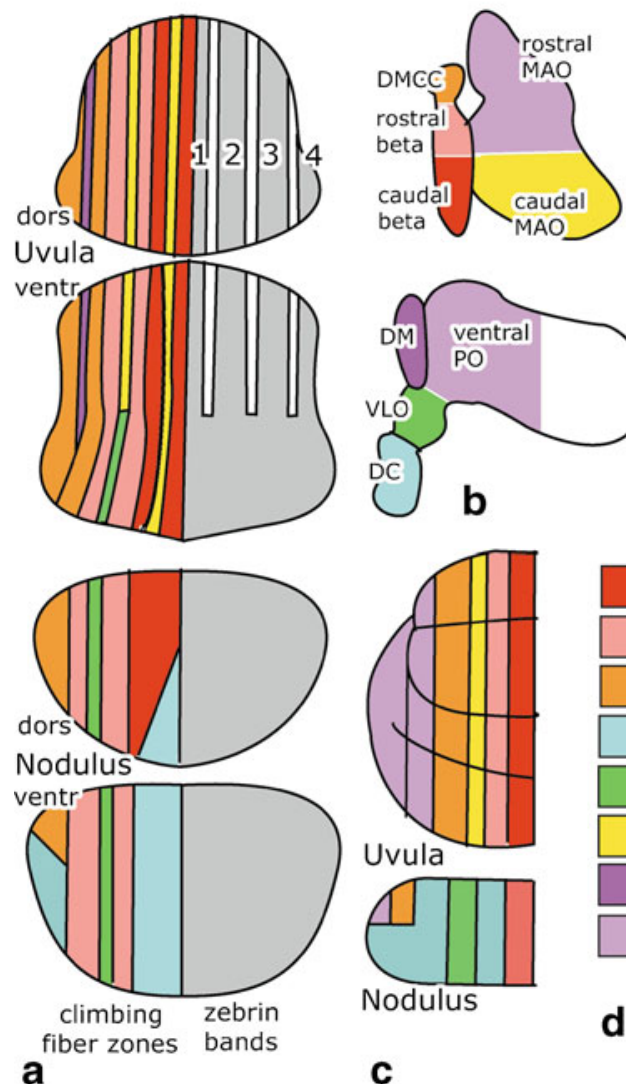

Nodulus

a
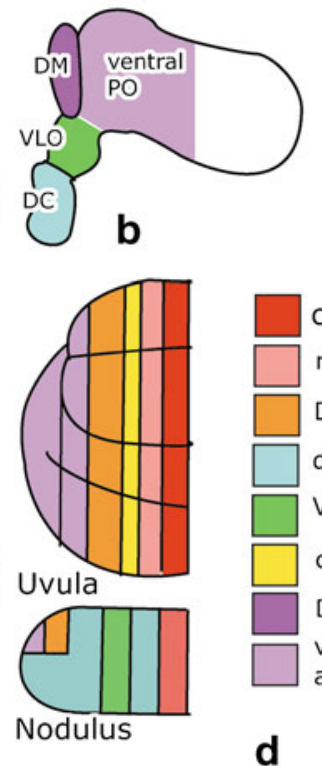

C

Fig. 9 Climbing fiber and efferent projections of the nodulus and the uvula. a Climbing fiber zones in the rat are illustrated in the left half of the lobules and the distribution of zebrin II bands on the right side [128]. b Diagram of the flattened inferior olive showing the origin of the climbing fibers innervating the nodulus and the uvula. c Climbing fiber zones in the nodulus according to Katayama and Nisimaru [130] and the uvula according to Sato and Barmack [131] in the rabbit. d Color code for the climbing fiber zones. e Optimal vestibular stimulation of Purkinje cell climbing fiber responses in the medial + nodulus (lobule 10) and uvula (9) of the rabbit. Purkinje cells responding both to static tilt and to stimulation in the plane of the ipsilateral posterior semicircular canal are illustrated as open red circles, cells responding to static tilt and rotation in the plane of the ipsilateral anterior canal as open light red squares, cells only tested for rotation are shown as filled symbols. Blue diamonds are cells

zebrin-negative zones were largely confirmed by Sugihara and Shinoda [48].

Zonal pattern in the distribution of the climbing fibers in the rabbit earlier has been described earlier for the nodulus [130] and uvula [131] of the rabbit (Fig. 9c). The two DCinnervated zones flanking a VLO-innervated zone were also found in the rabbit nodulus. In the uvula, the mediolateral positions of the projection from the caudal and rostral group beta and the DMCC are similar to the rat. Differences concern the presence of a caudal group beta projection in the medial nodulus, medial to the DC-innervated zone, the presence of climbing fibers from the ventral lamina of the principal olive and the rostral medial accessory olive in the lateral uvula, and the absence of multiple, narrow bands in

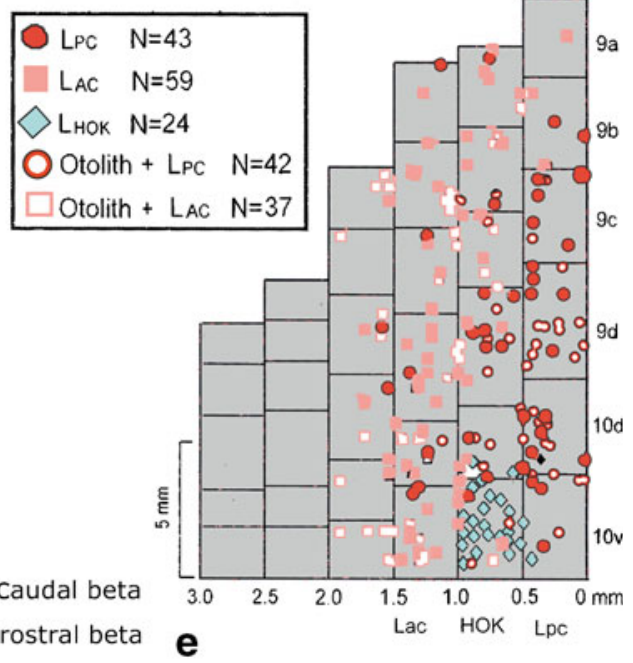

DMCC

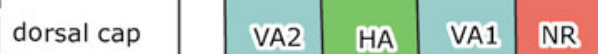

VLO

caudal MAO

DM

and rostral MAO sup vest nu med vest nu

p $\quad \mathbf{f}$

responding to head-body rotation around a vertical axis. Redrawn from Barmack and Yakhitsa [132]. f Projections of individual Purkinje cells in identified zones in the ventral nodulus in the rabbit. Zones identified by optokinetic stimulation correspond with the climbing fiber zones identified by Katayama and Nisimaru [130] in the nodulus (c). Redrawn from Wylie et al. [144]. Abbreviations: $D C$ dorsal cap, $D M$ dorsomedial group of the ventral lamina of the PO, DMCC dorsomedial cell column, $F$ fastigial nucleus, $H A$ Purkinje cell zone responsive to optokinetic stimulation around an oblique horizontal axis, $H O K$ Purkinje cells responding to optokinetic stimulation around the vertical axis, $L a c$ anterior semicircular canal, $L p c$ posterior semicircular canal, $M A O$ medial accessory olive, $P O$ principal olive, $V L O$ ventrolateral outgrowth, VA1, 2 Purkinje cell zones responsive to optokinetic stimulation around the vertical axis, $Y$ group $\mathrm{Y}$

the uvula, innervated by the dorsal group and the caudal medial accessory olive. These differences may be due to the use of different species, but the use of retrograde labeling from injections in the nodulus and the uvula also may have left narrow zones undetected. For primates, no information is available on these projections, with the exception of the presence of the DC-innervated zones in the medial and lateral nodulus (Voogd, unpublished observations).

The mediolateral position of climbing fibers from the caudal and rostral group beta was confirmed in a study of rabbits, recording climbing-fiber-evoked potentials in Purkinje cells in the medial nodulus and uvula on rotations in the planes of the anterior and posterior canals, stimulation of the otoliths, and optokinetic stimulation around the 
vertical axis [132] (Fig. 9e). Rotation in the plane of the posterior canal, transmitted by the caudal group beta produced responses in a medially located band of Purkinje cells, while rotation in the plane of the anterior canal, transmitted by the rostral group beta, activated Purkinje cells in a more lateral band. Many of these Purkinje cells also carry otolith information transmitted by the same olivary nuclei. A group of Purkinje cells responding to horizontal optokinetic stimulation, corresponding to the medial DC-innervated zone, was located in the medial part of the nodulus. These data are in accordance with the anatomical zonal pattern of the medial nodulus and uvula. Few recordings were made in the medial-most nodulus. The presence or absence of a medial caudal group betainnervated zone therefore cannot be determined.

When the distributions of mossy and climbing fibers are compared, climbing fibers from DC and VLO may interact with vestibular mossy fiber-parallel fiber input to the nodulus. In the uvula, climbing fibers from the group beta and the DMCC may interact with vestibular mossy fiber-parallel fibers in its ventral part and with pontine mossy fibers in its dorsal portion. Experiments on the collateralization of mossy and climbing fibers between the flocculus and the uvulanodulus in the rat showed that the collateralization of the climbing fibers remains restricted to the DC- and VLOinnervated zones. Collateral projections of the mossy fibers is more widespread and, in the case of the nodulus-uvula, bilaterally distributed [129]. Barmack and Yakhnitza [132] in rabbits and Yakhnitza and Barmack [133] in mice found simple spike and complex spike responses in the uvulanodulus to be sensitive to static roll tilt; none responded to horizontal vestibular stimulation. Complex spike response was modulated in phase with ipsilateral roll tilt, while simple spike responses were modulated out of phase. As shown in Fig. 9c, optimal planes of the complex spike responses were organized in a medial, caudal group beta-innervated zone, with optimal planes corresponding to the posterior semicircular canal and a rostral group beta-innervated zone, where optimal planes corresponded to the plane of the anterior canal. A similar but less precise zonal organization was found in mice.

The authors concluded that simple spike modulation in these Purkinje cells did not depend on their vestibular mossy fiber-parallel fiber input but rather on the zonally organized climbing fiber input. Parallel fiber signals to each Purkinje cell are presumably pan-directional. Moreover, simple spike responses are modulated out of phase with the signals from the mossy fiber-parallel fibers. If simple spike modulation was evoked by the mossy fiber-parallel fiber inputs, a sign reversal would be required. They propose that the modulation of the simple spikes depends on climbing-fiber-associated interneuronal inhibition of either granule cells by the Golgi cells or of Purkinje cells by stellate/basket cells. This proposition receives strong support from the observation of Barmack and Yakhnitza [134] that the axonal plexus of most Golgi cells, like the stellate/basket interneurons, is oriented parasagittally. Together with the observations of Ekerot and Jörntell [135] that climbing fibers inhibit topographically aligned Purkinje cells through the Golgi cells and molecular layer interneurons, this could explain how the zonal distribution of complex spike modulations is preserved in the distribution of the simple spike modulations.

The relationship between complex spike and simple spike activities during vestibular stimulation was studied also by Yakusheva et al. in macaque monkeys [136]. They found the strongest modulations during translation, a property not tested in earlier studies. Preferred directions for complex spike modulations clustered around the three cardinal axes, whereas the preferred directions for the simple spike modulations clustered around two $45^{\circ}$ oblique horizontal axes. Thus, in contrast to the findings by Barmack in rabbits, preferred directions for the simple spike and complex spike activities of individual cells were rarely aligned. In addition, the simple spikes did not always modulate out of phase with the complex spikes. Moreover, no sagittal plane organization of complex-spike-preferred directions to translation was found. Their failure to find any sign of the zonal organization of the climbing fiber input to the nodulus-uvula remains as of yet unexplained.

The corticonuclear and corticovestibular projections of the nodulus-uvula have been repeatedly studied in cats, monkeys, and rats [101, 137-142]. These lobules were found to be connected with the caudal fastigial and juxta-ventricular posterior interposed nuclei. The latter projection may very well correspond to Langer's basal interstitial nucleus [143] that consists of small cells in between and ventral to the interposed nuclei in the roof of the fourth ventricle. In rats and prosimians, the projection of the uvula to the fastigial nucleus may include its caudal visual portion [140, 142]. Moreover, projection from the uvula to the ventral posterior interposed and dentate nuclei was described in these species. In the vestibular nuclei, the nodulus innervates the periphery of the superior vestibular nucleus, the rostral parvocellular, and the caudal medial vestibular nucleus and adjacent parts of the spinal vestibular nucleus. The projections of the uvula are restricted to the dorsal superior vestibular and caudal medial vestibular nuclei. These vestibular projections are largely complementary to those of the flocculus.

The zonal origin of these projections was studied by Wylie et al. [144] in the rabbit nodulus, using intracellular labeling of individual Purkinje cells in zones identified with optokinetic stimulation (Fig. 9f). Their zonal pattern is similar to that found by Katayama and Nisimaru [130] (Fig. 9c). No responses to optokinetic stimulation were found in the medial NR zone. Purkinje cells in this region would be expected to receive vestibular, rather than 
optokinetic innervations, relayed by the group beta. Purkinje cells in this zone share projections to the basal interstitial nucleus and the medial vestibular nucleus with the other zones but, in addition, project to the fastigial nucleus. Projections to the medial vestibular nucleus most often target its caudal part. The VA1 and VA2 zones respond to optokinetic stimulation around a vertical axis, relayed by the dorsal cap. Their projections include the rostral parvocellular division of the medial vestibular nucleus and, in the case of the VA2 zone, the group Y. Purkinje cells in the intermediate HA zone respond to optokinetic stimulation around an oblique horizontal axis, relayed by the VLO. Its projections include the group Y and the superior and the caudal medial vestibular nuclei.

Access to the oculomotor system may be available for the nodulus through oculomotor relay cells in dorsal superior vestibular nucleus and the group $\mathrm{Y}$ and in the medial vestibular nucleus for rotations of the eye in the plane of the anterior and horizontal semicircular canal, respectively. Projections of the uvula may include the visual areas of the fastigial nucleus, the caudal posterior interposed nucleus, and the ventral dentate. Connections with oculomotor relay cells are presumably limited to the dorsal superior vestibular nucleus. Synaptic connections of these lobules with oculomotor relay cells have not been experimentally verified.

What are the functions of the uvula-nodulus in eye movements? Changes in open-loop gain of the VOR [145] and impairment of sustained downward pursuit in monkeys [146], probably, are dependent on the connections of the dorsal uvula with visual subdivisions of the posterior interposed and dentate nuclei. Solomon and Cohen [147] found stimulation of the nodulus and the ventral uvula in monkeys to discharge velocity storage in the VOR. They postulated that these lobules control the time constant of the yaw-axis component of slow-phase eye velocity produced by velocity storage. Barmack [114] emphasized the role of the nodulus and the ventral uvula in postural orientation in space, alluding to the changes in coding of postrotatory nystagmus from a gravitoinertial coordinate system into an orbital coordinate system following ablation of these lobules. Similar experiments in squirrel monkeys abolished slow-phase vertical OKN and OKAN eye velocity during roll [148]. It is not yet possible to explain these functions on the basis of the efferent circuitry of these lobules.

\section{Functional Imaging of Eye Movement Activities in the Human Cerebellum}

Over the past decade, various studies have employed functional imaging with the use of positron emission tomography (PET) and/or functional magnetic resonance imaging (fMRI) to reveal the cerebellar structures involved in eye movement control. These studies were aimed at detecting responses during all types of eye movements mentioned above including compensatory eye movements, saccadic eye movements, and smooth pursuit.

\section{Areas Associated with the Optokinetic Reflex}

Whereas natural vestibular stimulation is, apart from caloric stimulation [149], technically difficult to apply under the fMRI, optokinetic stimuli can be readily provided. The group of Dieterich and colleagues was among the first to report on cerebellar activation in human subjects during horizontal OKR using fMRI [150]. They observed bilateral activities in Crus I and II, lobules HV and HVI in the hemispheres, lobules $\mathrm{V}$ and IX in the vermis, the middle cerebellar peduncle, and the dentate nucleus, and later in another study also in the floccular lobe [151]. Unfortunately, they could not distinguish vertical from horizontal activation patterns in subtraction analyses following optokinetic stimulation in different directions. Similar activations were found by Bense [152], who also observed activation of the oculomotor vermis (VI-VIII). These studies might have been partially confounded by the possibility that the traditional black and white stripes used for optokinetic stimulation may also target the SP system [153-155]. Yet the use of limited lifetime dots for pure optokinetic stimulation may provide an underestimation of the areas involved because such stimulation has only yielded activity in lobule VI of the oculomotor vermis [154, 155], even though it is known from electrophysiological studies in both lower and higher mammals that areas such as the floccular lobe must be activated as well $[10,37,41,156]$.

\section{Areas Associated with Saccadic Eye Movements}

PET studies have indicated that areas in the cerebellar vermis can be activated in humans during both reflexive and voluntary saccadic eye movements [157, 158]. Using fMRI, Hayawaka et al. [159] reported bilateral activation related to visually guided saccades in the cerebellar vermis (VIIA) and hemispheres (Crus I and II, lobule HVI), which is consistent with neurophysiological data obtained in primates [160] while Honda et al. [161] showed bilateral activations in the dorsocaudal part of the vermis and superior semilunar lobule (Crus I) in the hemispheres following auditory-paced voluntary saccades. Dieterich et al. [150] reported activation in the quadrangular lobule (HV and VI), the superior semilunar lobule (Crus I) and inferior semilunar lobule (Crus II), and in the vermal lobules V and 
IX, with a small portion of lobule VIII during self-paced voluntary horizontal saccades. They suggested that the hemispherical signal changes were attributed to attention and timing, whereas the areas identified in the vermal structures were ascribed to ocular motor control. Similarly, Stephan et al. [162] reported activations in the cerebellar lobules HVI, Crus I and II, lobule HVIII, and the tonsil of the cerebellar hemispheres as well as in the oculomotor vermis, including lobules IX, VIIA and B, and VI, during visually guided horizontal saccades. Nitschke et al. [163] explored the role of the human cerebellum in the performance of saccadic eye movements with different cognitive demands. They investigated the functional significance of the postulated cerebro-cerebellar connections by looking for saccade-specific activation in the vermis and for memory-related activation of the hemisphere, which is connected with the parieto-prefrontal networks that subserve spatial working memory. They found activation of the cerebellar hemispheres (HVI, Crus I, HVIIB, HVIII) during sequences of memory-guided saccades in the visuospatial working memory task. This task included cueing of visuospatial attention, voluntary suppression of visual reflexive saccades, and use of visuospatial working memory. They interpreted the hemispheric activation as information processing involved in the initiation of saccades.

Cerebellar activation related to the adaptation of saccades [58, 164] was first studied by Desmurget et al. [165] using PET. They found activation in the oculomotor cerebellar vermis (lobules VI and VII) with an ipsilateral preponderance on the side to which the saccadic displacement was adapted. To separate the motor adaptation from the processes related to the visual error, Van Broekhoven et al. [166] employed a paradigm with a random intrasaccadic target step. Random intrasaccadic target steps do induce a postsaccadic visual error, but they do not lead to a gradual change in saccadic amplitudes. Both saccades towards random targets and saccades towards stationary targets did induce bilateral activation in vermal lobules VI and VII as well as lobule HVI. When the two conditions (random errors and no errors) were compared directly, random errors induced specific activation bilaterally in vermal lobules VIIA and VIII, lobules HVIII, HIX, and HX, and the tonsil and flocculus and in the left lobule HVIIB. The activity in these lobules may therefore represent the visual error signals used for the maintenance of saccadic accuracy.

Behavioral studies in humans suggest that the adaptation of reflexive saccades does not influence that of voluntary saccades or vice versa [167-169]. However, Schraa-Tam et al. did not find a significant difference in fMRI activation of the various cerebellar regions (lobules VI and VII and HVI) during the two types of saccadic adaptation [170]. These data suggest that the amplitudes for the two types of saccades are controlled by different sets of neurons within the same cerebellar regions and/or by different networks of other brain regions such as the cerebral cortex.

\section{Areas Associated with Smooth Pursuit}

Tanabe et al. [171] provided the first evidence using fMRI that the cerebellum plays a significant role in SP. Specific neurons that discharge for pursuit are primarily found in the flocculus, vermis, and hemispheres [172, 173]. Interestingly, they observed that activation in the hemispheres, but not in the vermis, decreased over time during the SP task. Possibly, this decrease reflects a change in attention because activation in the cerebellar hemispheres is more sensitive to attentiondependent repetition [150].

During SP, a moving target has to be followed against a stationary background. Yet, it can be argued that fixating a stationary target is similar in that the target also has to be stabilized on the retina. The main difference is the active eye movement component during SP. Schraa-Tam et al. [174] compared brain activation evoked by SP and fixation. To overcome difference in retinal stimulation, the fixation target was stationary against a moving background, whereas for SP, the stimulus was a single target moving against a stationary background. During SP, activations were found in lobules HVI and Crus I and centrally in vermal VI, whereas no significant activation was found during the fixation task. These data raise the possibility that the cerebellar activation during SP is induced by the active eye movement component.

The question of up to what extent the network underlying SP differs from that underlying OKR has been studied by Konen et al. [175] and Schraa-Tam et al. [154, 155]. Konen et al. found bilateral activation in lobules IV$\mathrm{V}$ and the left Crus I and II when SP was compared with rest. However, when predictable SP was compared with OKR, they only found bilateral activation of lobules IV-V. In contrast, Schraa-Tam et al. [155] found bilateral activation in vermal lobule VI and the Crus I area for the SP task and only in the right lobule VI area for the OKR task; in a direct comparison, lobule VI showed stronger activation during SP than OKR. This stronger activation may be explained by the fact that SP is under voluntary control, which requires constant recalibration and updating of the position of the moving objects.

\section{Synopsis and Future Directions}

There are at least four cerebellar regions in primates that are concerned with eye movements; these include the floccular lobe, oculomotor vermis, ansiform lobule, and dorsal paraflocculus (Table 1). The floccular lobe is concerned with 
adaptation of the VOR and probably also that of the OKR, SP, and related head movements; the oculomotor vermis controls the adaptation of saccades and probably also that of SP; the ansiform lobule may subserve mainly SP control; and the dorsal paraflocculus may contribute to both SP and visually guided movements of extraocular body parts [42, 97, 98, 107, 176-178]. As also holds true for nonvisuomotor regions of the cerebellum [101, 107], the climbing fiber inputs to the four visuomotor regions of the cerebellar cortex align well with the specific outputs of the Purkinje cell zones of these regions (compare climbing fiber inputs with efferents in Table 1 and Fig. 7). In general, the target nuclei of the nonvisuomotor Purkinje cell zones receive a collateral input from the climbing fibers that innervate these zones, and the nucleo-olivary pathways that connect these nuclei with the subdivisions of the inferior olive are reciprocal [100, 107]. However, for the visuomotor parts of the floccular lobe, this direct reciprocity probably only holds true for some of the loops involved in vertical eye movement control [10]. The mossy fiber projections to the different visuomotor areas of the cerebellum share some of their sources but mostly differ (Table 1). Subpopulations of the nuclei that provide these mossy fibers may have a more restricted distribution, and the precise topographical relations between the different mossy fiber afferents in primates remain to be further investigated. The observations of Barmack $[132,133]$ on the modulation of simple spikes by the climbing fibers and the role of the interneurons therein have important implications for our understanding of cerebellar cortical circuitry. For the nodulus-uvula, the consequences of these observations for the control of eye movements and the role of the transformation by the Purkinje cells of semicircular canal and otolith input into a signal encoding inertial motion, as shown by Yakhusheva and Angelaki [127, 136], should be further explored.

Our account of the cerebellar connections underlying visuomotor control outlined above may have some implications for the current ideas on oculomotor control in general. For example, the current concepts of Ilg and Thier [176] and Lisberger [156, 179] distinguish parallel descending pathways from the FEF and postrolandic visual areas that would converge in the dorsal pontine nuclei and/or the visuomotor cerebellum, and they imply that the corresponding converged mossy fiber inputs terminate in the floccular lobe so as to integrate control of pursuit behavior with that of other oculomotor reflexes. However, the recipients of postrolandic visual areas, the dorsolateral pontine nuclei, do not project to the floccular lobe [24, 25], whereas the FEF do provide input to the flocculus via the NRTP [83, 84]. Thus, as far as we can deduce from the current insights reviewed here, the floccular lobe does not provide an optimal downstream locus for integrating SP 
processing with postrolandic visual processing. In this regard, it may be worthwhile to further explore the SPrelated inputs to the dorsal paraflocculus in primates because this part of the visuomotor cerebellum does receive input from the part of the dorsolateral pontine nuclei that is innervated by the postrolandic visual areas [23, 24]. Alternatively, one could investigate the integration of SP processing in the floccular lobe with that in the oculomotor vermis, either at the level of the cerebellar and vestibular nuclei and/or even further downstream in the feedback pathways to the cerebral cortex. After all, SP-related functional imaging activities in the oculomotor vermis (lobules IV-VI) often occur concomitantly with those in the flocculus and visual cerebral cortical areas [151, 152, 171].

Although the sensitivity of functional imaging studies of the cerebellum during eye movements may be limited, the positive results obtained with them largely do correspond with the experimental data $[151,152,154$, $155,171]$, and they do in fact give impetus to new lines of physiological studies on various occasions. For example, the observations obtained with random dot patterns with limited lifetime activation suggest further exploration of the role of vermal lobule VI in OKR control [154]; the activations of Crus I during both reflexive and voluntary saccades suggest further exploration of the role of this region in integrating cerebellar visuomotor functions with complementary nonvisual explorative processing [170], and the prominent activation of vermal lobule VIII and lobule HVIII following random saccadic adaptation promises interesting new findings for electrophysiological experiments on error-related saccadic signaling in these regions [166]. Taken together, the anatomical, physiological, and functional imaging data on the visuomotor cerebellum reviewed here should encourage us to study cerebellar function not only in a multidisciplinary approach but also in a multiregional approach trying to integrate the contributions of different parts of the cerebellum to a single behavioral task.

\begin{abstract}
Acknowledgements We kindly thank the Dutch Organization for Medical Sciences (ZonMw; CIDZ), Life Sciences (ALW; CIDZ), Senter (Neuro-Bsik; CIDZ), Prinses Beatrix Fonds (JvdG; CIDZ), and the SENSOPAC, CEREBNET, and C7 programs of the European Community (CIDZ) for their financial support.
\end{abstract}

Conflict of Interest (COI) Statement There is no conflict of interest.

Open Access This article is distributed under the terms of the Creative Commons Attribution Noncommercial License which permits any noncommercial use, distribution, and reproduction in any medium, provided the original author(s) and source are credited.

\section{References}

1. Voogd J, Gerrits NM, Hess DT. Parasagittal zonation of the cerebellum in macaques: an analysis based on acetylcholinesterase histochemistry. In: Glickstein M, Yeo C, Stein J, editors. Cerebellum and neuronal plasticity. New York: Plenum; 1987. p. 15-39.

2. Tan J, Simpson JI, Voogd J. Anatomical compartments in the white matter of the rabbit flocculus. J Comp Neurol. 1995;356:1-22.

3. Simpson JI, Graf W. Eye-muscle geometry and compensatory eye movements in lateral-eyed and frontal-eyed animals. Ann NY Acad Sci. 1981;374:20-30.

4. Distler C, Mustari MJ, Hoffmann KP. Cortical projections to the nucleus of the optic tract and dorsal terminal nucleus and to the dorsolateral pontine nucleus in macaques: a dual retrograde tracing study. J Comp Neurol. 2002;444:144-58.

5. Büttner-Ennever JA, Cohen B, Horn AK, Reisine H. Efferent pathways of the nucleus of the optic tract in monkey and their role in eye movements. J Comp Neurol. 1996;373:90-107.

6. Mustari MJ, Fuchs AF, Kaneko CR, Robinson FR. Anatomical connections of the primate pretectal nucleus of the optic tract. J Comp Neurol. 1994;349:111-28.

7. Holstege G, Collewijn H. The efferent connections of the nucleus of the optic tract and the superior colliculus in the rabbit. J Comp Neurol. 1982;209:139-75.

8. Ito M, Nisimaru N, Yamamoto M. Specific patterns of neuronal connexions involved in the control of the rabbit's vestibuloocular reflexes by the cerebellar flocculus. J Physiol. 1977;265:833-54.

9. Langer T, Fuchs AF, Chubb MC, Scudder CA, Lisberger SG. Floccular efferents in the rhesus macaque as revealed by autoradiography and horseradish peroxidase. J Comp Neurol. 1985;235:26-37.

10. De Zeeuw CI, Wylie DR, DiGiorgi PR, Simpson JI. Projections of individual Purkinje cells of identified zones in the flocculus to the vestibular and cerebellar nuclei in the rabbit. J Comp Neurol. 1994;349:428-47.

11. Highstein SM, Reisine H. Synaptic and functional organization of vestibulo-ocular reflex pathways. Prog Brain Res. 1979;50:431-42.

12. Yamamoto M, Shimoyama I, Highstein SM. Vestibular nucleus neurons relaying excitation from the anterior canal to the oculomotor nucleus. Brain Res. 1978;148:31-42.

13. De Zeeuw CL, Koekkoek SK. Signal processing in the C2 module of the flocculus and its role in head movement control. Prog Brain Res. 1997;114:299-320.

14. Simpson JI, Wylie DR, De Zeeuw CI. On climbing fiber signals and their consequence(s). Behav Brain Res. 1996;19:384-98.

15. Tan J, Gerrits NM, Nanhoe R, Simpson JI, Voogd J. Zonal organization of the climbing fiber projection to the flocculus and nodulus of the rabbit: a combined axonal tracing and acetylcholinesterase histochemical study. J Comp Neurol. 1995;356:23-50.

16. van der Steen J, Simpson JI, Tan J. Functional and anatomic organization of three-dimensional eye movements in rabbit cerebellar flocculus. J Neurophysiol. 1994;72:31-46.

17. Giolli RA, Blanks RH, Lui F. The accessory optic system: basic organization with an update on connectivity, neurochemistry, and function. Prog Brain Res. 2006;151:407-40.

18. Langer T, Fuchs AF, Scudder CA, Chubb MC. Afferents to the flocculus of the cerebellum in the rhesus macaque as revealed by retrograde transport of horseradish peroxidase. J Comp Neurol. 1985;235:1-25.

19. Belknap DB, McCrea RA. Anatomical connections of the prepositus and abducens nuclei in the squirrel monkey. J Comp Neurol. 1988;268:13-28. 
20. Büttner-Ennever JA, Horn AK. Pathways from cell groups of the paramedian tracts to the floccular region. Ann NY Acad Sci. 1996;781:532-40.

21. Giolli RA, Gregory KM, Suzuki DA, Blanks RH, Lui F, Betelak KF. Cortical and subcortical afferents to the nucleus reticularis tegmenti pontis and basal pontine nuclei in the macaque monkey. Vis Neurosci. 2001;18:725-40.

22. Giolli RA, Torigoe Y, Blanks RH, McDonald HM. Projections of the dorsal and lateral terminal accessory optic nuclei and of the interstitial nucleus of the superior fasciculus (posterior fibers) in the rabbit and rat. J Comp Neurol. 1988;277:608-20.

23. Wells GR, Hardiman MJ, Yeo CH. Visual projections to the pontine nuclei in the rabbit: orthograde and retrograde tracing studies with WGA-HRP. J Comp Neurol. 1989;279:629-52.

24. Glickstein M, Gerrits N, Kralj-Hans I, Mercier B, Stein J, Voogd J. Visual pontocerebellar projections in the macaque. J Comp Neurol. 1994;349:51-72.

25. Xiong G, Nagao S. The lobulus petrosus of the paraflocculus relays cortical visual inputs to the posterior interposed and lateral cerebellar nuclei: an anterograde and retrograde tracing study in the monkey. Exp Brain Res. 2002;147:2522-63.

26. Hess BJ, Blanks RH, Lannou J, Precht W. Effects of kainic acid lesions of the nucleus reticularis tegmenti pontis on fast and slow phases of vestibulo-ocular and optokinetic reflexes in the pigmented rat. Exp Brain Res. 1989;74:63-79.

27. Miyashita E, Tamai Y. Subcortical connections of frontal 'oculomotor' areas in the cat. Brain Res. 1989;502:75-87.

28. Blazquez PM, Davis-Lopez e Carrizosam MA, Heiney SA, Highstein SM. Neuronal substrates of motor learning in the velocity storage generated during optokinetic stimulation in the squirrel monkey. J Neurophysiol. 2007;97:1114-26.

29. Dean P, Porrill J. Oculomotor anatomy and the motor-error problem: the role of the paramedian tract nuclei. Prog Brain Res. 2008;171:177-86.

30. Tanaka M, Lisberger SG. Enhancement of multiple components of pursuit eye movement by microstimulation in the arcuate frontal pursuit area in monkeys. J Neurophysiol. 2002;87:802-18.

31. Lisberger SG. The latency of pathways containing the site of motor learning in the monkey vestibulo-ocular reflex. Science. 1984;225:74-6.

32. Lisberger SG, Pavelko TA. Vestibular signals carried by pathways subserving plasticity of the vestibulo-ocular reflex in monkeys. J Neurosci. 1986;6:346-54.

33. Lisberger SG, Pavelko TA. Brain stem neurons in modified pathways for motor learning in the primate vestibulo-ocular reflex. Science. 1988;242:771-3.

34. Miles FA, Fuller JH. Adaptive plasticity in the vestibulo-ocular responses of the rhesus monkey. Brain Res. 1974;80:512-6.

35. du Lac S. Candidate cellular mechanisms of vestibulo-ocular reflex plasticity. Ann NY Acad Sci. 1996;781:489-98.

36. du Lac S, Raymond JL, Sejnowski TJ, Lisberger SG. Learning and memory in the vestibulo-ocular reflex. Annu Rev Neurosci. 1995; 18:409-41.

37. Faustich BM, Onori KA, du Lac S. Comparison of plasticity and development of mouse optokinetic and vestibulo-ocular reflexes suggests different gain control mechanisms. Vis Res. 2004;44: 3419-27.

38. Hirata Y, Highstein SM. Analysis of the discharge pattern of floccular Purkinje cells in relation to vertical head and eye movement in the squirrel monkey. Prog Brain Res. 2000;124:221-32.

39. Lisberger SG. Neural basis for motor learning. J Neurophysiol. 1994;72:974-98.

40. Blazquez PM, Hirata Y, Heiney SA, Green AM, Highstein SM. Cerebellar signatures of vestibulo-ocular reflex motor learning. J Neurosci. 2003;29:9742-51.
41. Partsalis AM, Zhang Y, Highstein SM. Dorsal Y group in the squirrel monkey. II. Contribution of the cerebellar flocculus to neuronal responses in normal and adapted animals. J Neurophysiol. 1995;73:632-50.

42. Robinson FR, Fuchs AF. The role of the cerebellum in voluntary eye movements. Annu Rev Neurosci. 2001;24:981-1004.

43. Noda H, Sugita S, Ikeda Y. Afferent and efferent connections of the oculomotor region of the fastigial nucleus in the macaque monkey. J Comp Neurol. 1990;302:330-48.

44. Büttner U, Büttner-Ennever JA. Present concepts of oculomotor organization. Prog Brain Res. 2006;151:1-42.

45. Nieuwenhuys R, van Huijzen C, Voogd J. The human central nervous system. 4th ed. Heidelberg: Springer; 2008.

46. Yamada J, Noda H. Afferent and efferent connections of the oculomotor cerebellar vermis in the macaque monkey. J Comp Neurol. 1987;265:224-41.

47. Ruigrok TJ, Voogd J. Organization of projections from the inferior olive to the cerebellar nuclei in the rat. J Comp Neurol. 2000;426:209-28.

48. Sugihara I, Shinoda Y. Molecular, topographic, and functional organization of the cerebellar cortex: a study with combined aldolase $\mathrm{C}$ and olivocerebellar labeling. J Neurosci. 2004;24:8771-85.

49. Akaike T. The tectorecipient zone in the inferior olivary nucleus in the rat. J Comp Neurol. 1992;320:398-414.

50. Brodal P. The projection from the nucleus reticularis tegmenti pontis to the cerebellum in the rhesus monkey. Exp Brain Res. 1980;38:29-36.

51. Gerrits NM, Voogd J. The nucleus reticularis tegmenti pontis and the adjacent rostral paramedian reticular formation: differential projections to the cerebellum and the caudal brain stem. Exp Brain Res. 1986;62:29-45.

52. Gerrits NM, Voogd J. The projection of the nucleus reticularis tegmenti pontis and adjacent regions of the pontine nuclei to the central cerebellar nuclei in the cat. J Comp Neurol. 1987;258:52-69.

53. Mihailoff GA. Cerebellar nuclear projections from the basilar pontine nuclei and nucleus reticularis tegmenti pontis as demonstrated with PHA-L tracing in the rat. J Comp Neurol. 1993;330:130-46.

54. Gruart A, Delgado-Garcia JM. Signalling properties of identified deep cerebellar nuclear neurons related to eye and head movements in the alert cat. J Physiol. 1994;478:37-54.

55. McCrea RA, Baker R, Delgado-Garcia J. Afferent and efferent organization of the prepositus hypoglossi nucleus. Prog Brain Res. 1979;50:653-65.

56. McCrea RA, Horn AK. Nucleus prepositus. Prog Brain Res. 2006;151:205-30.

57. De Zeeuw CI, Wentzel P, Mugnaini E. Fine structure of the dorsal cap of the inferior olive and its GABAergic and nonGABAergic input from the nucleus prepositus hypoglossi in rat and rabbit. J Comp Neurol. 1993;327:63-82.

58. Hopp JJ, Fuchs AF. The characteristics and neuronal substrate of saccadic eye movement plasticity. Prog Neurobiol. 2004;72:27-53.

59. Kojima Y, Soetedjo R, Fuchs AF. Changes in simple spike activity of some Purkinje cells in the oculomotor vermis during saccade adaptation are appropriate to participate in motor learning. J Neurosci. 2010;30:3715-27.

60. Scudder CA, Kaneko CS, Fuchs AF. The brainstem burst generator for saccadic eye movements: a modern synthesis. Exp Brain Res. 2002;142:439-62.

61. Catz N, Dicke PW, Thier P. Cerebellar-dependent motor learning is based on pruning a Purkinje cell population response. Proc Natl Acad Sci U S A. 2008;105:7309-14.

62. Barash S, Melikyan A, Sivakov A, Zhang M, Glickstein M, Thier P. Saccadic dysmetria and adaptation after lesions of the cerebellar cortex. J Neurosci. 1999;19:10931-9. 
63. Sato H, Noda H. Saccadic dysmetria induced by transient functional decortication of the cerebellar vermis [corrected]. Exp Brain Res. 1992;88:455-8.

64. Takagi M, Tamargo R, Zee DS. Effects of lesions of the cerebellar oculomotor vermis on eye movements in primate: binocular control. Prog Brain Res. 2003;142:19-33.

65. Ohtsuka K, Noda H. The effect of microstimulation of the oculomotor vermis on discharges of fastigial neurons and visuallydirected saccades in macaques. Neurosci Res. 1991;10:290-5.

66. Optican LM, Robinson DA. Cerebellar-dependent adaptive control of primate saccadic system. J Neurophysiol. 1980;44:1058-76.

67. Scudder CA, McGee DM. Adaptive modification of saccade size produces correlated changes in the discharges of fastigial nucleus neurons. J Neurophysiol. 2003;90:1011-26.

68. Kojima Y, Iwamoto Y, Robinson FR, Noto CT, Yoshida K. Premotor inhibitory neurons carry signals related to saccade adaptation in the monkey. J Neurophysiol. 2008;99:220-30.

69. Robinson FR. The role of the cerebellar posterior interpositus nucleus in saccades. I. Effects of temporary lesions. J Neurophysiol. 2000;84:1289-303.

70. Lynch JC, Tian JR. Cortico-cortical networks and corticosubcortical loops for the higher control of eye movements. Prog Brain Res. 2005;151:461-501.

71. Baizer JS, Desimone R, Ungerleider LG. Comparison of subcortical connections of inferior temporal and posterior parietal cortex in monkeys. Vis Neurosci. 1993;10:59-72.

72. Borostyankoi-Baldauf $Z$, Herczeg L. Parcellation of the human pretectal complex: a chemoarchitectonic reappraisal. Neurosci Res. 2002;110:527-40.

73. Glickstein M, May 3rd JG, Mercier BE. Corticopontine projection in the macaque: the distribution of labelled cortical cells after large injections of horseradish peroxidase in the pontine nuclei. J Comp Neurol. 1985;235:343-59.

74. Schmahmann JD, Pandya DN. Anatomical investigation of projections to the basis pontis from posterior parietal association cortices in rhesus monkey. J Comp Neurol. 1989;289:53-73.

75. Schmahmann JD, Pandya DN. Projections to the basis pontis from the superior temporal sulcus and superior temporal region in the rhesus monkey. J Comp Neurol. 1991;308:224-48.

76. Schmahmann JD, Pandya DN. Prelunate, occipitotemporal, and parahippocampal projections to the basis pontis in rhesus monkey. J Comp Neurol. 1993;337:94-112.

77. Glickstein M, May J, Mercier B. Visual corticopontine and tectopontine projections in the macaque. Arch Ital Biol. 1990;128:273-93.

78. Huerta MF, Kaas JH. Supplementary eye field as defined by intracortical microstimulation: connections in macaques. J Comp Neurol. 1990;293:299-330.

79. Huerta MF, Krubitzer LA, Kaas JH. Frontal eye field as defined by intracortical microstimulation in squirrel monkeys, owl monkeys, and macaque monkeys: I. Subcortical connections. J Comp Neurol. 1986;253:415-39.

80. Leichnetz GR, Gonzalo-Ruiz A. Prearcuate cortex in the Cebus monkey has cortical and subcortical connections like the macaque frontal eye field and projects to fastigialrecipient oculomotor-related brainstem nuclei. Brain Res Bull. 1996;41:1-29.

81. Shook BL, Schlag-Rey M, Schlag J. Primate supplementary eye field: I. Comparative aspects of mesencephalic and pontine connections. J Comp Neurol. 1990;301:618-42.

82. Stanton GB, Goldberg ME, Bruce CJ. Frontal eye field efferents in the macaque monkey: I. Subcortical pathways and topography of striatal and thalamic terminal fields. J Comp Neurol. 1988;271:473-92.

83. Xiong G, Hiramatsu T, Nagao S. Corticopontocerebellar pathway from the prearcuate region to hemispheric lobule VII of the cerebellum: an anterograde and retrograde tracing study in the monkey. Neurosci Lett. 2002;322:173-6.

84. Suzuki DA, Yamada T, Yee RD. Smooth-pursuit eye-movementrelated neuronal activity in macaque nucleus reticularis pontis. $\mathrm{J}$ Neurophysiol. 2003;89:2146-58.

85. Crandall WF, Keller EL. Visual and oculomotor signals in nucleus reticularis tegmenti pontis in alert monkey. J Neurophysiol. 1985;54:1326-45.

86. Suzuki DA, Yamada T, Hoedema R, Yee RD. Smooth-pursuit eye-movement deficits with chemical lesions in macaque nucleus reticularis tegmenti pontis. J Neurophysiol. 1999;82:1178-86.

87. May JG, Keller EL, Suzuki DA. Smooth pursuit eye movement deficits with chemical lesions in the dorsolateral pontine nucleus of the monkey. J Neurophysiol. 1988;59:952-77.

88. Mustari MJ, Fuchs AF, Wallman J. Response properties of dorsolateral pontine units during smooth pursuit in the rhesus macaque. J Neurophysiol. 1988;60:664-86.

89. Suzuki DA, May JG, Keller EL, Yee RD. Visual motion response properties of neurons in dorsolateral pontine nucleus of alert monkey. J Neurophysiol. 1990;63:37-59.

90. Ono S, Das VE, Economides JR, Mustari MJ. Modeling of smooth pursuit-related neuronal responses in the DLPN and NRTP of the rhesus macaque. J Neurophysiol. 2005;93:10816.

91. Ono S, Das VE, Mustari MJ. Gaze-related response properties of DLPN and NRTP neurons in the rhesus macaque. J Neurophysiol. 2004;91:2484-500.

92. Hiramatsu T, Ohki M, Kitazawa H, Xiong G, Kitamura T, Yamada J, et al. Role of primate cerebellar lobulus petrosus of paraflocculus in smooth pursuit eye movement control revealed by chemical lesion. Neurosci Res. 2008;60:250-8.

93. Ohki M, Kitazawa H, Hiramatsu T, Kaga K, Kitamura T, Yamada $\mathrm{J}$, et al. Role of primate cerebellar hemisphere in voluntary eye movement control revealed by lesion effects. J Neurophysiol. 2009;101:934-47.

94. Noda H, Mikami A. Discharges of neurons in the dorsal paraflocculus of monkeys during eye movements and visual stimulation. J Neurophysiol. 1986;56:1129-246.

95. Marple-Horvat DE, Stein JF. Neuronal activity in the lateral cerebellum of trained monkeys, related to visual stimuli or to eye movements. J Physiol. 1990;428:595-614.

96. Oyster CW, Takahashi E, Collewijn H. Direction-selective retinal ganglion cells and control of optokinetic nystagmus in the rabbit. Vis Res. 1972;12:183-93.

97. Ono S, Brostek L, Nuding U, Glasauer S, Büttner U, Mustari MJ. The response of MSTd neurons to perturbations in target motion during ongoing smooth-pursuit eye movements. J Neurophysiol. 2010;103:519-30.

98. Medina JF, Lisberger SG. Encoding and decoding of learned smooth-pursuit eye movements in the floccular complex of the monkey cerebellum. J Neurophysiol. 2009;102:2039-54.

99. van Kan PLE, Houk JC, Gibson AR. Output organization of intermediate cerebellum of the monkey. J Neurophysiol. 1993;69:57-73.

100. De Zeeuw CI, Ruigrok TJH. Olivary projecting neurons in the nucleus of Darkschewitsch in the cat receive excitatory monosynaptic input from the cerebellar nuclei. Brain Res. 1994;653:345-50.

101. Voogd J. The cerebellum of the cat: structure and fiber connections. Thesis Leiden. Assen: Van Gorcum. University of Leiden; 1964.

102. May PJ, Porter JD, Gamlin PD. Interconnections between the primate cerebellum and midbrain near-response regions. J Comp Neurol. 1992;315:98-116.

103. Prevosto V, Graf W, Ugolini G. Cerebellar inputs to intraparietal cortex areas LIP and MIP: functional frameworks for adaptive 
control of eye movements, reaching, and arm/eye/head movement coordination. Cereb Cortex. 2010;20:214-28.

104. Faugier-Grimaud S, Ventre J. Anatomic connections of the inferior parietal cortex (area7) with subcortical structures related to vestibulo-ocular function in a monkey (Macaca fascicularis). J Comp Neurol. 1989;280:1-14.

105. Porter CM, van Kan PE, Horn KM, Bloedel JR, Gibson AR. Functional divisions of the cat rMAO. Abstr Soc Neurosci. 1983;19:499-10.

106. Fujita H, Oh-Nishi A, Obayashi S, Sugihara I. Organization of the marmoset cerebellum in three-dimensional space: lobulation, aldolase $\mathrm{C}$ compartmentalization and axonal projection. J Comp Neurol. 2010;518:1764-91.

107. Glickstein M, Sultan F, Voogd J. Functional localization in the cerebellum. Cortex. 2009; in press.

108. Kitazawa H, Xiong G, Hiramatsu T, Ohki M, Nagao S. Difference of climbing fiber input sources between the primate oculomotor-related cerebellar vermis and hemisphere revealed by a retrograde tracing study. Neurosci Lett. 2009;462:10-3.

109. Monakow KH Hartmann-von, Akert K, Künzle H. Projections of precentral and premotor cortex to the red nucleus and other midbrain areas in Macaca fascicularis. Exp Brain Res. 1979;34:91-105.

110. Kuypers HGJM, Lawrence DG. Cortical projections to the red nucleus and the brain stem in the rhesus monkey. Brain Res. 1967;4:151-88.

111. Clower DM, Dum RP, Strick PL. Basal ganglia and cerebellar inputs to 'AIP'. Cereb Cortex. 2005;15:913-20.

112. Strominger NL, Truscott TC, Miller RA, Royce GJ. An autoradiographic study of the rubro-olivary tract in the rhesus monkey. J Comp Neurol. 1979;183:33-45.

113. Voogd J, Pardoe J, Ruigrok TJ, Apps R. The distribution of climbing and mossy fiber collateral branches from the copula pyramidis and the paramedian lobule: congruence of climbing fiber cortical zones and the pattern of zebrin banding within the rat cerebellum. J Neurosci. 2003;23:4645-56.

114. Barmack NH. Central vestibular system: vestibular nuclei and posterior cerebellum. Brain Res Bull. 2003;60:511-41.

115. Voogd J, Barmack NH. Oculomotor cerebellum. Prog Brain Res. 2005;151:231-68.

116. Gerrits NM, Epema AH, van Linge A, Dalm E. The primary vestibulocerebellar projection in the rabbit: absence of primary afferents in the flocculus. Neurosci Lett. 1989;105:27-33.

117. Kevetter GA, Perachio AA. Distribution of vestibular afferents that innervate the sacculus and posterior canal in the gerbil. J Comp Neurol. 1986;254:410-24.

118. Maklad A, Fritzsch B. Partial segregation of posterior crista and saccular fibers to the nodulus and uvula of the cerebellum in mice, and its development. Brain Res Dev Brain Res. 2003;140:223-36.

119. Newlands SD, Vrabec JT, Purcell IM, Stewart CM, Zimmerman BE, Perachio AA. Central projections of the saccular and utricular nerves in macaques. J Comp Neurol. 2003;466:31-47.

120. Purcell IM, Perachio AA. Peripheral patterns of terminal innervation of vestibular primary afferent neurons projecting to the vestibulocerebellum in the gerbil. J Comp Neurol. 2001;433:48-61.

121. Carleton SC, Carpenter MB. Distribution of primary vestibular fibers in the brainstem and cerebellum of the monkey. Brain Res. 1984;294:281-98.

122. Thunnissen IE, Epema AH, Gerrits NM. Secondary vestibulocerebellar mossy fiber projection to the caudal vermis in the rabbit. J Comp Neurol. 1989;290:262-77.

123. Barmack NH, Baughman RW, Eckenstein FP, Shojaku H. Secondary vestibular cholinergic projection to the cerebellum of rabbit and rat as revealed by choline acetyltransferase immunohistochemistry, retrograde and orthograde tracers. J Comp Neurol. 1992;317:250-70.
124. Barmack NH, Yakhnitsa V. Distribution of granule cells projecting to focal Purkinje cells in mouse uvula-nodulus. Neurosci. 2008;156:216-21.

125. Angelaki DE, Yakusheva TA. How vestibular neurons solve the tilt/translation ambiguity. Comparison of brainstem, cerebellum, and thalamus. Ann NY Acad Sci. 2009;1164:19-28.

126. Angelaki DE, Yakusheva TA, Green AM, Dickman JD, Blazquez PM. Computation of egomotion in the macaque cerebellar vermis. Cerebellum. 2010;9:174-82.

127. Yakusheva TA, Shaikh AG, Green AM, Blazquez PM, Dickman JD, Angelaki DE. Purkinje cells in posterior cerebellar vermis encode motion in an inertial reference frame. Neuron. 2007;54:973-85.

128. Voogd J, Gerrits NM, Ruigrok TJ. Organization of the vestibulocerebellum. Ann NY Acad Sci. 1996;781:553-79.

129. Ruigrok TJ. Collateralization of climbing and mossy fibers projecting to the nodulus and flocculus of the rat cerebellum. $\mathrm{J}$ Comp Neurol. 2003;466:278-98.

130. Katayama S, Nisimaru N. Parasagittal zonal pattern of olivonodular projections in rabbit cerebellum. Neurosci Res. 1988;5:424-38.

131. Sato Y, Barmack NH. Zonal organization of olivocerebellar projections to the uvula in rabbits. Brain Res. 1985;359:281-91.

132. Barmack NH, Yakhnitsa V. Cerebellar climbing fibers modulate simple spikes in Purkinje cells. J Neurosci. 2003;23:7904-16.

133. Yakhnitsa V, Barmack NH. Antiphasic Purkinje cell responses in mouse uvula-nodulus are sensitive to static roll-tilt and topographically organized. Neuroscience. 2006;143:615-26.

134. Barmack NH, Yakhnitsa V. Functions of interneurons in mouse cerebellum. J Neurosci. 2008;28:1140-52.

135. Ekerot CF, Jörntell $\mathrm{H}$. Parallel fiber receptive fields: a key to understanding cerebellar operation and learning. Cerebellum. 2003;2:101-9.

136. Yakusheva T, Blazquez PM, Angelaki DE. Relationship between complex and simple spike activity in macaque caudal vermis during three-dimensional vestibular stimulation. J Neurosci. 2010;30:8111-26.

137. Angaut P, Brodal A. The projection of the "vestibulocerebellum" onto the vestibular nuclei in the cat. Arch Ital Biol. 1967;105:441-79.

138. Dow RS. Efferent connections of the flocculonodular lobe in Macaca mulatta. J Comp Neurol. 1938;68:288-305.

139. Haines DE. Cerebellar corticovestibular fibers of the posterior lobe in a prosimian primate, the lesser bushbaby (Galago senegalensis). J Comp Neurol. 1975;160:363-98.

140. Haines DE. Cerebellar corticonuclear and corticovestibular fibers of the flocculonodular lobe in a prosimian primate (Galago senegalensis). J Comp Neurol. 1977;174:607-30.

141. Sugihara I, Shinoda Y. Molecular, topographic, and functional organization of the cerebellar nuclei: analysis by three-dimensional mapping of the olivonuclear projection and aldolase $\mathrm{C}$ labeling. $\mathrm{J}$ Neurosci. 2007;27:9696-710.

142. Tabuchi T, Umetani T, Yamadori T. Corticonuclear and corticovestibular projections from the uvula in the albino rat: differential projections from sublobuli of the uvula. Brain Res. 1989;492:176-86.

143. Langer TP. Basal interstitial nucleus of the cerebellum: cerebellar nucleus related to the flocculus. J Comp Neurol. 1985;235:38-47.

144. Wylie DR, De Zeeuw CI, DiGiorgi PL, Simpson JI. Projections of individual Purkinje cells of identified zones in the ventral nodulus to the vestibular and cerebellar nuclei in the rabbit. J Comp Neurol. 1994;349:448-63.

145. Heinen SJ, Keller EL. Cerebellar uvula involvement in visual motion processing and smooth pursuit control in monkey. Ann NY Acad Sci. 1992;656:775-82.

146. Walker MF, Tian J, Shan X, Tamargo RJ, Ying H, Zee DS. Lesions of the cerebellar nodulus and uvula in monkeys: effect on otolith-ocular reflexes. Prog Brain Res. 2008;171:167-72. 
147. Solomon D, Cohen B. Stimulation of the nodulus and uvula discharges velocity storage in the vestibulo-ocular reflex. Exp Brain Res. 1994;102:57-68.

148. Igarashi M, Takeda N, Chae S. Uvula-nodulus and gravity direction (a study on vertical optokinetic-oculomotor functions). Acta Astronaut. 1992;27:25-30.

149. Naito Y, Tateya I, Hirano S, Inoue M, Funabiki K, Toyoda H, et al. Cortical correlates of vestibulo-ocular reflex modulation: a PET study. Brain. 2003;126:1562-78.

150. Dieterich M, Bucher SF, Seelos KC, Brandt T. Cerebellar activation during optokinetic stimulation and saccades. Neurology. 2000;54:148-55.

151. Dieterich M, Muller-Schunk S, Stephan T, Bense S, Seelos K, Yousry TA. Functional magnetic resonance imaging activations of cortical eye fields during saccades, smooth pursuit, and optokinetic nystagmus. Ann NY Acad Sci. 2009;1164:282-92.

152. Bense S, Janusch B, Vucurevic G, Bauermann T, Schlindwein P, Brandt $\mathrm{T}$, et al. Brainstem and cerebellar fMRI-activation during horizontal and vertical optokinetic stimulation. Exp Brain Res. 2006; 174:312-23.

153. Bense S, Janusch B, Schlindwein P, Bauermann T, Vucurevic G, Brandt $\mathrm{T}$, et al. Direction-dependent visual cortex activation during horizontal optokinetic stimulation (fMRI study). Hum Brain Mapp. 2006;27:296-305.

154. Schraa-Tam CK, van der Lugt A, Smits M, Frens MA, van Broekhoven PC, van der Geest JN. fMRI of optokinetic eye movements with and without a contribution of smooth pursuit. J Neuroimaging. 2008;18:158-67.

155. Schraa-Tam CK, van der Lugt A, Smits M, Frens MA, van Broekhoven PC, van der Geest JN. Differences between smooth pursuit and optokinetic eye movements using limited lifetime dot stimulation: a functional magnetic resonance imaging study. Clin Physiol Funct Imaging. 2009;29:245-54.

156. Kahlon M, Lisberger SG. Changes in the responses of Purkinje cells in the floccular complex of monkeys after motor learning in smooth pursuit eye movements. J Neurophysiol. 2000;84:2945-60.

157. Dejardin S, Dubois S, Bodart JM, Schiltz C, Delinte A, Michel $\mathrm{C}$, et al. PET study of human voluntary saccadic eye movements in darkness: effect of task repetition on the activation pattern. Eur J Neurosci. 1998;10:2328-36.

158. Sweeney JA, Mintun MA, Kwee S, Wiseman MB, Brown DL, Rosenberg DR, et al. Positron emission tomography study of voluntary saccadic eye movements and spatial working memory. J Neurophysiol. 1996;75:454-68.

159. Hayakawa Y, Nakajima T, Takagi M, Fukuhara N, Abe H. Human cerebellar activation in relation to saccadic eye movements: a functional magnetic resonance imaging study. Ophtalmologica. 2002;216:399-405.

160. Noda H, Fujikado T. Topography of the oculomotor area of the cerebellar vermis in macaques as determined by microstimulation. J Neurophysiol. 1987;58:359-78.

161. Honda M, Zee DS, Hallett M. Cerebellar control of voluntary saccadic movement in humans. fMRI study. Soc Neurosci Abstracts. 1977; 15:1189.

162. Stephan T, Mascolo A, Yousry TA, Bense S, Brandt T, Dieterich $\mathrm{M}$. Changes in cerebellar activation pattern during two successive sequences of saccades. Hum Brain Mapp. 2002;16:63-70.

163. Nitschke MF, Binkofski F, Buccino G, Posse S, Erdmann C, Kompf D, et al. Activation of cerebellar hemispheres in spatial memorization of saccadic eye movements: an fMRI study. Hum Brain Mapp. 2004;22:155-64

164. Pelisson D, Goffart L, Guillaume A. Control of saccadic eye movements and combined eye/head gaze shifts by the medioposterior cerebellum. Prog Brain Res. 2003;142:69-89.

165. Desmurget M, Pelisson D, Grethe JS, Alexander GE, Urquizar $\mathrm{C}$, Prablanc C, et al. Functional adaptation of reactive saccades in humans: a PET study. Exp Brain Res. 2000;132:243-59.

166. van Broekhoven PC, Schraa-Tam CK, van der Lugt A, Smits M, Frens MA, van der Geest JN. Cerebellar contributions to the processing of saccadic errors. Cerebellum. 2009;8:403-15.

167. Alahyane N, Salemme R, Urquizar C, Cotti J, Guillaume A, Vercher JL, et al. Oculomotor plasticity: are mechanisms of adaptation for reactive and voluntary saccades separate? Brain Res. 2007;1135:107-21.

168. Erkelens CJ, Hulleman J. Selective adaptation of internally triggered saccades made to visual targets. Exp Brain Res. 1993;93:157-64.

169. Gaveau V, Alahyane N, Salemme R, Desmurget M. Selfgenerated saccades do not modify the gain of adapted reactive saccades. Exp Brain Res. 2005;162:526-31.

170. Schraa-Tam CK, van Broekhoven P, van der Geest JN, Frens MA, Smits M, van der Lugt A. Cortical and cerebellar activation induced by reflexive and voluntary saccades. Exp Brain Res. 2009;192:175-87.

171. Tanabe J, Tregellas J, Miller D, Ross RG, Freedman R. Brain activation during smooth-pursuit eye movements. Neuroimage. 2002; 17:1315-24.

172. Eckmiller R. Neurol control of pursuit eye movements. Physiol Rev. 1987;67:797-857.

173. Leigh RJ, Zee DS. The neurology of eye movements. 3rd ed. Oxford: Oxford University Press; 1999.

174. Schraa-Tam CK, van der Lugt A, Frens MA, Smits M, van Broekhoven PC, van der Geest JN. An fMRI study on smooth pursuit and fixation suppression of the optokinetic reflex using similar visual stimulation. Exp Brain Res. 2008;185:535-44.

175. Konen CS, Kleiser R, Seitz RJ, Bremmer F. An fMRI study of optokinetic nystagmus and smooth-pursuit eye movements in humans. Exp Brain Res. 2005;165:203-16.

176. Ilg UJ, Thier P. The neural basis of smooth pursuit eye movements in the rhesus monkey brain. Brain Cogn. 2008;68:229-40.

177. Shinmei Y, Yamanobe T, Fukushima J, Fukushima K. Purkinje cells of the cerebellar dorsal vermis: simple-spike activity during pursuit and passive whole-body rotation. J Neurophysiol. 2002;87:1836-49.

178. Takagi M, Zee DS, Tamargo RJ. Effects of lesions of the oculomotor vermis on eye movements in primate: saccades. J Neurophysiol. 1998;80:1911-31.

179. Tanaka M, Lisberger SG. Role of arcuate frontal cortex of monkeys in smooth pursuit eye movements. II. Relation to vector averaging pursuit. J Neurophysiol. 2002;87:2700-14.

180. Schmahmann JD, Doyon J, Toga AW, Petrides M, Evans A. MRI atlas of the human cerebellum. London: Academic; 2000.

181. Sato Y, Kawasaki T, Ikarashi K. Afferent projections from the brainstem to the three floccular zones in cats. II. Mossy fiber projections. Brain Res. 1983;272:37-48.

182. Akaogi K, Sato Y, Ikarashi K, Kawasaki T. Mossy fiber projections from the brain stem to the nodulus in the cat. An experimental study comparing the nodulus, the uvula and the flocculus. Brain Res. 1994;638:12-20. 